\title{
Solid-State NMR Studies on Supramolecular Chemistry
}

\author{
Michele R. Chierotti and Roberto Gobetto
}

Universitá degli Studi di Torino, Torino, Italy

1 Introduction

2 Solid-State NMR Techniques

3 Structure Characterization

4 Dynamics in Supramolecular Systems

5 Conclusions

Acknowledgments

References

\section{INTRODUCTION}

Noncovalent interactions, such as hydrogen bond (HB) and $\pi-\pi$ interactions, are key features in supramolecular chemistry where self-assembly of carefully chosen building blocks is of central importance.

A full knowledge of supramolecular systems represents an important challenge since it implies the comprehension of the atomic level of the structure, dynamics, as well as the characterization of the weak interactions involved. Indeed, their understanding allows the design of periodic and organized supramolecular structures with desired properties.

$\mathrm{X}$-ray crystallography is certainly the best choice in many cases, but the technique often fails when the long-range crystal order is lost or when dealing with hydrogen positions due to intrinsic limitations.

Supramolecular Chemistry: From Molecules to Nanomaterials. Edited by Philip A. Gale and Jonathan W. Steed.

(c) 2012 John Wiley \& Sons, Ltd. ISBN: 978-0-470-74640-0.
Among the massive array of experimental methods, based on many different physical phenomena, able to afford structural information, NMR spectroscopy plays a central role. Indeed, parameters such as chemical shifts $\left(\delta_{\text {iso }}\right)$, chemical shift tensors $\left(\delta_{11}, \delta_{22}, \delta_{33}\right)$, homonuclear and heteronuclar dipolar interactions (D), chemical shift anisotropy $(\mathrm{CSA})$, relaxation times $\left(\mathrm{T}_{1}, \mathrm{~T}_{2}, \mathrm{~T}_{1 \rho}\right)$, and lineshape $(\Delta \varpi)$ allow the investigation of short range structural environments (HB and nuclear proximities) as well as the evaluation of slow and fast dynamic processes.

The advantages of NMR techniques are as follows:

1. the unique selectivity that allows to differentiate chemically distinct environments on the basis of the chemical shift ${ }^{1,2}$ combined, if necessary, with spectral editing experiments;

2. the possibility to investigate the presence and the strength of $\mathrm{HBs}$ from the ${ }^{1} \mathrm{H}$ chemical shift of hydrogen-bonded signal in ${ }^{1} \mathrm{H}$ MAS (magic angle spinning) experiments ${ }^{3}$;

3. the ability to determine homonuclear $\left({ }^{1} \mathrm{H}-{ }^{1} \mathrm{H}\right.$, ${ }^{13} \mathrm{C}-{ }^{13} \mathrm{C}$, etc. $)$ and heteronuclear $\left({ }^{1} \mathrm{H}-{ }^{13} \mathrm{C}\right.$ and ${ }^{1} \mathrm{H}-{ }^{31} \mathrm{P}$, ${ }^{13} \mathrm{C}-{ }^{15} \mathrm{~N}$, etc.) proximities or distances from $2 \mathrm{D}$ spectra $^{4,5}$ or from redor-like experiments ${ }^{6}$;

4. the wide range of the timescale of motions that can be investigated at variable temperature (VT) with a large set of different NMR parameters. ${ }^{7}$

Owing to all these possibilities the NMR techniques have been used in many aspects of supramolecular chemistry: from biological (protein, polypeptide, etc.) to polymer systems and also in the crystal engineering field. ${ }^{8}$

However, besides the advantages, it is worth citing some drawback related, for instance, to the relatively low sensitivity in comparison to other techniques. This leads to 
the need of relatively large sample amounts and/or longer experimental times. Furthermore, the high instrumental cost and the need of a strong user expertise may potentially limit a wide-ranging use of the technique.

The aim of this chapter is the employment of the potentiality of SSNMR (solid-state NMR) techniques to access information at a molecular level in supramolecular systems. Intriguing examples are presented in order to provide a select overview of the information obtainable from its parameters.

After a brief introduction focused on the NMR approach to the study of solid-state systems, the chapter is organized into two parts that presents new methods for probing, first, the structure and, second, the dynamics in supramolecular systems.

\section{SOLID-STATE NMR TECHNIQUES}

Presently, by means of solution-state NMR spectroscopy one can even determine the complete three-dimensional structure of proteins of molecular masses approaching $50 \mathrm{kDa}$, while in the solid state the fast isotropic molecular tumbling leading to the observation of inherently highresolution solution-state spectra is absent. Indeed, SSNMR is dominated by anisotropic interactions such as the dipolar and quadrupolar couplings (between nuclear magnetic moments of two different spins the former and between nuclear electric quadrupole with the electric field gradient at the nucleus the latter) and the chemical shielding (small anisotropic magnetic fields either added to or subtracted from the external field due to circulating currents of electrons). ${ }^{7}$ Their spatial dependence produces featureless broad and complex resonances in powdered samples.

However, the dipolar and quadrupolar (at least at the first order level) interactions as well as the CSA have one angular dependence in common, summarized by the expression $3 \cos ^{2} \theta-1$, where $\theta$ is the angle between the interaction vector and the static magnetic field. In a powder sample where the molecules are randomly oriented it is possible to make this expression equal to zero and, thus, to remove the linebroadening effects, by rotating the sample at a value of $\theta=54.7^{\circ}$. This is commonly known as magic angle (MA) and the technique is called MAS. Since the speed limit (determined by the rotor diameter) cannot exceed few tens of $\mathrm{kHz}, \mathrm{MAS}$ is often unable to completely remove interactions that can be of the order of hundreds of $\mathrm{kHz}$ or even $\mathrm{MHz}$. The remaining part of such interactions (dipolar, CSA, or quadrupolar) is seen in the spectra as a distortion of the signal or by the appearance of spinning sidebands (SSB).

Cross-polarization (CP) combined with MAS is the most important signal enhancement technique in SSNMR for observing low abundant spins. ${ }^{9}$ In this pulse sequence the polarization is first transferred from the abundant spins $I$, typically ${ }^{1} \mathrm{H}$, to the dilute spins $S$ (typically ${ }^{13} \mathrm{C}$ or ${ }^{29} \mathrm{Si}$ ), and the signal from spins $S$ is then observed. This technique is also used as a building-block for many two-dimensional (2D) pulse sequences.

In the case of ${ }^{1} \mathrm{H}$ (and ${ }^{19} \mathrm{~F}$ ) strong homonuclear dipolar interactions (up to hundreds of $\mathrm{kHz}$ ) dominate the resonance lines, and broad featureless signals are obtained since MAS spinning rates are too slow to provide efficient decoupling. One of the most important recent advances in SSNMR has been the development of MAS probes able to spin the sample up to $70 \mathrm{kHz}$ with rotor diameter of $1.7 \mathrm{~mm}$ : these probes opened promising applications in moderately sized organic solids since some ${ }^{1} \mathrm{H}$ resonances due to particular chemically distinct proton environments can be resolved in ${ }^{1} \mathrm{H}$ MAS NMR spectra.

Alternatively, special pulse sequence, known as CRAMPS (combined rotation and multipulse sequence), ${ }^{10}$ combine the MAS rotation with synchronized rotations of the nuclear spins using rf pulses allowing enhanced resolution of proton spectra. They have been constructed in such a way that at certain points the effect of the dipolar interaction on the nuclear magnetization is zero. Currently, pulse sequences such as frequency-switched Lee-Goldburg (FSLG), ${ }^{11}$ phase-modulated Lee-Goldburg (PMLG), ${ }^{12}$ and DUMBO (decoupling using mind-boggling optimization), ${ }^{13}$ allow to obtain high-resolution spectra at both high and low spinning speed $(5-60 \mathrm{kHz})$. They can be applied in a windowless fashion (i.e., continuous RF irradiation, since there is no requirement for windows in which data points are acquired) in the indirect dimension of a $2 \mathrm{D}$ experiment, ${ }^{10}$ or as a windowed sequence such as $\mathrm{W}-\mathrm{PMLG}^{14}$ or $\mathrm{w}-\mathrm{DUMBO}^{15}$ in the direct acquisition dimension. All the ${ }^{1} \mathrm{H}$ techniques are particularly useful since $\mathrm{HBs}$ are key interactions in supramolecular systems and protons are in high natural abundance avoiding isotopic enrichment even for a small amount of sample.

If, on the one hand, the anisotropic interactions have the significant drawback of hindering the peak resolution, on the other hand, they contain valuable structural and dynamic information.

For instance, the dipolar interaction between two coupled spins is proportional to $1 / r^{3}$ following the equation:

$$
\mathrm{D}_{\mathrm{IS}}=\left(\frac{\mu_{0}}{4 \pi}\right) \frac{\gamma_{I} \gamma_{S} \hbar}{r_{\mathrm{IS}}^{3}}
$$

where $\mathrm{D}_{\mathrm{IS}}$ is the dipolar coupling between nuclear spins $I$ and $S, \mathrm{r}_{I S}$ is the internuclear distance $I-S, \mu_{0}$ is the permeability of free space, $\gamma_{I}$ and $\gamma_{S}$ are the gyromagnetic ratio of spins $I$ and $S$ respectively, $\hbar$ is the Planck's constant divided by $2 \pi$. Therefore, SSNMR experiments 
which provide access to this interaction can be used to determine specific distance constraints.

Indeed, much effort has been devoted to the development of pulse sequences that recouple specific dipolar couplings that would otherwise be removed by MAS, that is, by applying pulses at proper intervals in order to counteract the effect of MAS on the heteronuclear dipolar coupling. ${ }^{16,17}$

In the last decades a series of homonuclear and heteronuclear recoupling experiments have been developed that combine a 2D approach with fast MAS and dipolar multiple-quantum NMR spectroscopy. In this way, the chemical shift resolution of different chemical environments allows sites of interest to be distinguished and fully identified, and then it is possible to obtain structural information since dipole-dipole couplings are sensitive to the distances between the coupled nuclei as well as to the orientation of the internuclear vector.

It has been shown that the $2 \mathrm{D}{ }^{1} \mathrm{H}$ double-quantum (DQ) MAS at about $30 \mathrm{kHz}$, offers new information about the proximity or connectivity of different nuclei. In the ${ }^{1} \mathrm{H}$ DQ NMR spectroscopy, the generation of DQ coherences requires the existence of a dipolar coupling between two protons. Thus, the observation of particular DQ peaks implies the existence of a sufficient dipolar coupling between the respective nuclei. In this way, detailed information about internuclear proximities can be readily obtained from the $2 \mathrm{D}$ peaks. Under MAS conditions the excitation of DQ coherences requires the use of a recoupling pulse sequence. ${ }^{16,17}$ The most used is the BABA scheme, ${ }^{18}$ whose acronym comes from the presence of very closely spaced pulses (back-to-back) in the time domain.

The analysis of rotor-encoded ${ }^{1} \mathrm{H}$ DQ MAS SSB patterns enables the quantitative determination of the internuclear distance for a well-isolated pair of protons. ${ }^{19}$ The ${ }^{1} \mathrm{H}$ DQ MAS use in the supramolecular field has been reviewed by Brown and Spiess. ${ }^{20}$

By means of its CRAMPS analogue, ${ }^{1} \mathrm{H}$ DQ CRAMPS, the observation of correlation peaks in $2 \mathrm{D}$ spectra are indicative of $\mathrm{H}-\mathrm{H}$ proximities under $3.5 \AA .^{21}$

2D heteronuclear correlation (HETCOR) spectroscopy is a cornerstone technique for many assignment strategies and is the method of choice for distance measurements through time-oscillatory magnetization build-up curves, REDOR (rotational echo double resonance) dephasing curves or rotor-encoded SSB analysis.

A large array of heteronuclear $\mathrm{H}-\mathrm{X}$ dipolar recoupling pulse sequences, developed mainly for $\mathrm{X}={ }^{13} \mathrm{C}$ and ${ }^{15} \mathrm{~N},{ }^{4,22}$ combine information on ${ }^{1} \mathrm{H}$-chemical shift and ${ }^{1} \mathrm{H}-\mathrm{X}$ dipole-dipole coupling.

One way to determine heteronuclear dipolar couplings with MAS is to perform separated local field spectroscopy (SLF) experiments, a 2D NMR protocol which resolves for

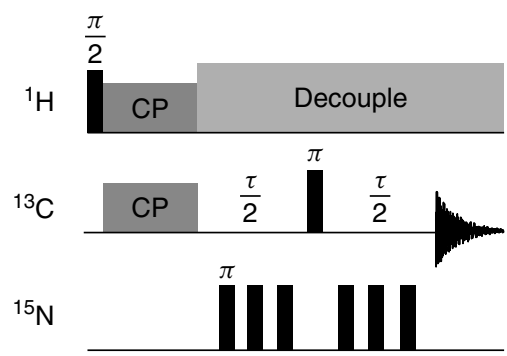

(a)
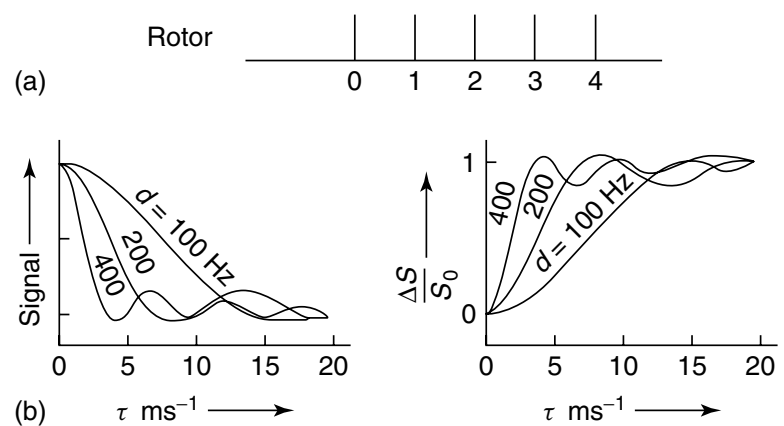

Figure 1 (a) The REDOR pulse sequence. Two experiments have to be performed with ${ }^{13} \mathrm{C}$ as the observed spin in both cases. In the reference experiment the ${ }^{13} \mathrm{C}-{ }^{15} \mathrm{~N}$ dipolar coupling is refocused at the end of every rotor period, as normal under MAS. In the second experiment, this refocusing is prevented by a series of rotor-synchronized p-pulses applied to the ${ }^{15} \mathrm{~N}$ spin. ${ }^{13} \mathrm{C}$ spin spectra are collected for several different lengths of dephasing time each of which multiple of $2 \tau_{r}\left(\tau_{r}=\right.$ rotor period). (b) Dephasing curves which show the amount of dephasing relative to the reference signal intensity $\left(\Delta S / S_{0}\right)$. (Reproduced from Ref. 26. (c) Wiley-VCH, 2002.)

each chemically inequivalent site $\mathrm{S}$ in the sample its ${ }^{1} \mathrm{H}-\mathrm{S}$ dipolar SSB manifolds. ${ }^{23,24}$

A typical pulse sequence for the evaluation of internuclear distances, the REDOR, ${ }^{25}$ is obtained by the application of rotor-synchronized $\pi$ pulses on the dipolar coupled $I$ spins, applied twice per rotor period, with a single $S$ spin $\pi$ pulse applied halfway during the sequence to refocus the dipolar interaction between the two nuclei (Figure 1a). ${ }^{25,26}$

When the $S-I$ dipolar coupling is reintroduced, the decay of the $S$ magnetization is dependent on the dephasing effect of the heteronuclear dipolar coupling as depicted in Figure 1(b).

The technique mainly applied on isotopic labeled compounds has been used in many different cases. By fitting the experimental dephasing curve of a sample of ${ }^{13} \mathrm{C}-{ }^{15} \mathrm{~N}$ labeled $(10 \%)$ glycine a ${ }^{13} \mathrm{C}-{ }^{15} \mathrm{~N}$ dipolar coupling constant of $195 \mathrm{~Hz}$ was obtained that corresponds to a ${ }^{13} \mathrm{C}-{ }^{15} \mathrm{~N}$ internuclear distance of $2.47 \AA$. The limit value of the heteronuclear dipolar coupling constant is around $25 \mathrm{~Hz}$, then useful structure information can be obtained at distances that cannot exceed $5 \AA$ in the case of ${ }^{13} \mathrm{C}-{ }^{15} \mathrm{~N}$ and $7.5 \AA$ in the case of ${ }^{13} \mathrm{C}-{ }^{31} \mathrm{P}$ distances. 


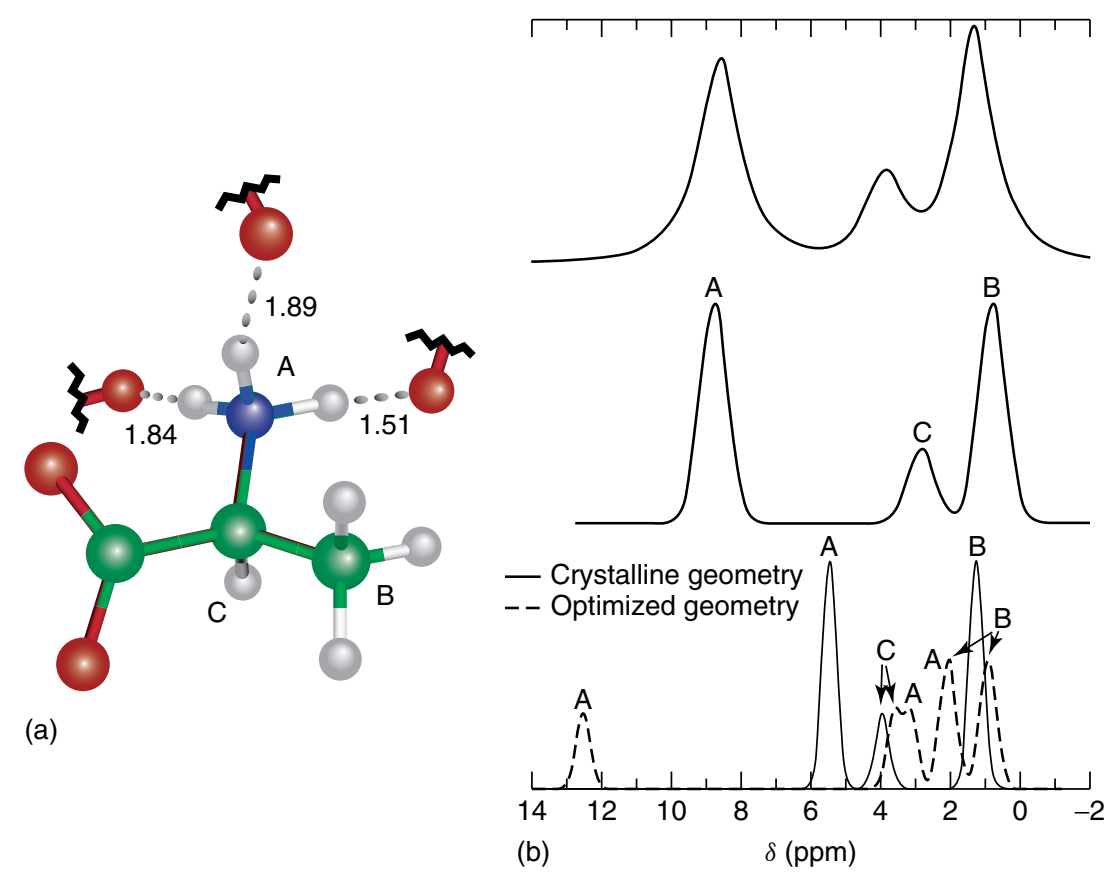

Figure 2 (a) Structure of alanine in the periodic crystal lattice with labeling A, B, and $\mathrm{C}$ of the protons. (b) ${ }^{1} \mathrm{H}$ spectra of alanine. Top: experimental ${ }^{1} \mathrm{H}$ MAS spectrum; middle: computed in the fully periodic crystal; bottom: computed spectrum of a gas phase molecule in crystalline molecular and in optimized geometry. (Reproduced from Ref. 30. (c) American Chemical Society, 2006.)

$\mathrm{R}^{2}$ (Rotational Resonance) recovers the dipolar coupling by choosing the MAS spinning frequency such that the isotropic chemical shift difference between the two nuclei of interest $(\Delta \sigma)$ is equal to an integer multiple of the MAS frequency $\left(\omega_{r}\right): \Delta \sigma=n \omega_{r} \cdot{ }^{27}$

These techniques can be applied also for $\mathrm{S}-\mathrm{X}$ (with $\mathrm{X}$ having $I>0.5)$ dipole couplings in its REAPDOR (rotational-echo adiabatic-passage double-resonance) version. $^{28}$

Beside the multitude of techniques based on magnetization transfer through the homonuclear dipolar coupling to obtain through-space ${ }^{13} \mathrm{C}$ chemical shift correlations, in the last decade sequences to determine through-bond carbon-13 connectivities have been developed. Often, the through-bond connectivies are necessary to establish unambiguous assignments of the NMR spectra, before throughspace interactions can be used to determine structure.

The INADEQUATE experiment, well-known liquid-state technique to establish direct scalar connectivites in the ${ }^{13} \mathrm{C}$ skeleton, has been successfully applied in the solid state in its standard and refocused versions that yield antiphase and in-phase correlations, respectively. ${ }^{29}$

The calculation of chemical shifts using quantumchemical methods affords new insights in the extraction of structural and dynamics information allowing reliable assignments of the experimental data. Supramolecular systems present packing effects that can be tackled by a combined approach that combines experimental ${ }^{1} \mathrm{H}$ data with quantum-chemical calculations Such a validation is obtained preferentially on systems that have known structures and a limited complexity. An example of comparison of experimental and computed ${ }^{1} \mathrm{H}$ NMR chemical shift spectra for alanine in the periodic lattice is reported in Figure 2. ${ }^{30}$ A sufficient agreement with the experimental data is found, especially for the hydrogen-bonded protons. In the static calculation, different NMR chemical shifts at $14.3,6.4$, and $5.6 \mathrm{ppm}$ are expected for the three $\mathrm{NH}_{3}$ protons characterized by different geometry of HBs. In the real sample, the $\mathrm{NH}_{3}{ }^{+}$group is rotating, resulting in a single NMR line for the amino protons at $8.6 \mathrm{ppm}$. About the same value $(8.8 \mathrm{ppm})$ is obtained when averaging the calculated chemical shifts.

In the case of quadrupolar interaction the signals appear severely distorted and often the center of gravity is changed. A combination of pulse schemes (multiple quantum magic angle spinning (MQMAS)) allows the separation of the chemical shift and the quadrupolar coupling. ${ }^{31}$ In the last decades many other $1 \mathrm{D}$ and 2D pulse sequences have been proposed that enable scientists to obtain structure and dynamic information about supramolecular systems that were previously very hard to study with conventional X-ray crystallography and neutron scattering. ${ }^{7}$ This multiparameter, multinuclear approach represents a formidable tool for structural investigation since each NMR signal can be univocally assigned to the respective nucleus in the precise environment as a report at molecular level 

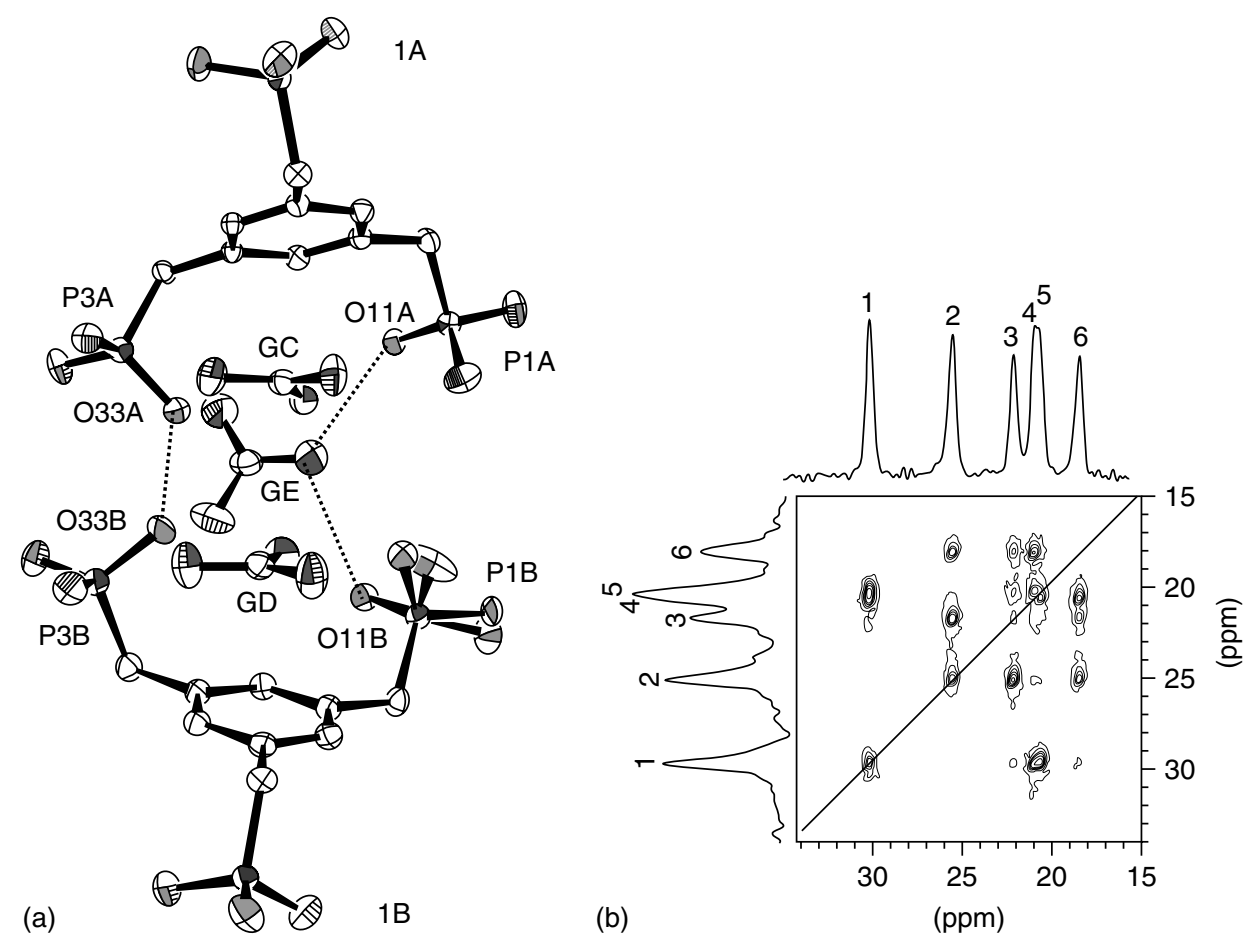

Figure 3 (a) X-ray structure of the sample $\left[\mathrm{CH}_{6} \mathrm{~N}_{3}\right]_{3}\left[\mathrm{C}_{9} \mathrm{H}_{13} \mathrm{O}_{9} \mathrm{P}_{3}\right]\left[\mathrm{C}_{9} \mathrm{H}_{14} \mathrm{O}_{9} \mathrm{P}_{3}\right]$. (b) ${ }^{1} \mathrm{H}$ decoupled ${ }^{31} \mathrm{P} 2 \mathrm{D}$ through-space SQ-SQ (single quantum-single quantum) spectrum of mixture of single crystals and microcrystal of compound $\left[\mathrm{CH}_{6} \mathrm{~N}_{3}\right]_{3}\left[\mathrm{C}_{9} \mathrm{H}_{13} \mathrm{O}_{9} \mathrm{P}_{3}\right]\left[\mathrm{C}_{9} \mathrm{H}_{14} \mathrm{O}_{9} \mathrm{P}_{3}\right]$ obtained by a shearing transformation of the experimental SQ-DQ spectrum. (Reproduced from Ref. 32. (C) Royal Society of Chemistry, 2004.)

of the proximities and/or the nature of the strong and weak interaction involved. Of course almost all the nuclei of the periodic table are NMR active and then complementary data can be combined by a multinuclear study. For example, the very sensitive ${ }^{31} \mathrm{P}$ nucleus represents a valuable method for detecting supramolecular arrangements in phosphorus containing systems. The supramolecular structure obtained by cocrystallization of benzene1,3,5-tris(methylenephosphonic acid) $\left[\mathrm{C}_{9} \mathrm{H}_{15} \mathrm{O}_{9} \mathrm{P}_{3}\right]$ with guanidinium chloride $\left[\mathrm{CH}_{6} \mathrm{~N}_{3}\right] \mathrm{Cl}$, yields the compound of formula that possesses six crystallographically inequivalent phosphorus atoms, and then six different ${ }^{31} \mathrm{P}$ peaks in the ${ }^{31} \mathrm{P}$ SSNMR spectrum. ${ }^{32}$ Their assignment has been performed by through-space single quantum-double quantum (SQ-DQ) correlation experiments (Figure 3) leading to two possible assignments of the six crystallographic $\mathrm{P}$ sites to the corresponding resonances in the $1 \mathrm{D}^{31} \mathrm{P}$ MAS NMR spectrum.

\section{STRUCTURE CHARACTERIZATION}

Supramolecular chemistry utilizes weak and reversible noncovalent interactions, such as HB and aromatic $\pi-\pi$ interactions, metal coordination, hydrophobic and van der Waals forces, and/or electrostatic effects to assemble molecules into multimolecular complexes. ${ }^{33}$ Therefore, a complete understanding of the supramolecular forces (preferred geometries, competitive bonds, strength, and recognition pattern) is a prerequisite for a rational design of desired solid architectures.

\subsection{The hydrogen bond}

The most powerful organizing force in molecular assembly is certainly represented by the strong, highly selective, and directional HBs. Several techniques have been used for the HB detection and characterization, but due to their intrinsic limitation, methods of choice are mainly IR and NMR spectroscopy. Since in the solid-state signals are not averaged by solvent effects or by rapid exchange processes present in solution, the SSNMR approach allows an accurate evaluation of the HB local environment and strength.

An increasing number of ${ }^{1} \mathrm{H}$ studies ${ }^{34}$ is focused on the direct chemical shift measurement of protons in $\mathrm{HB}$ obtained at very high spinning speed (up to $70 \mathrm{kHz}$ ). In particular, the proton is increasingly deshielded with increasing the $\mathrm{HB}$ strength, which leads to ${ }^{1} \mathrm{H}$ high frequency shifts far from aliphatic and aromatic signals (Scheme 1). ${ }^{35}$ The main feature of this technique is that the magnitude of the 


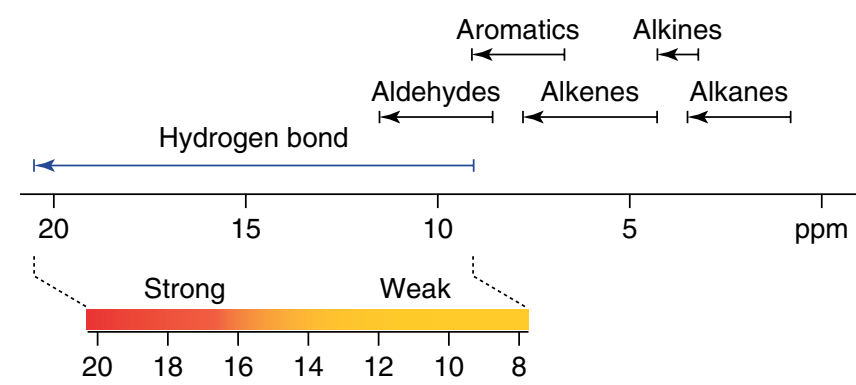

Scheme $1 \quad{ }^{1} \mathrm{H}$ chemical shift scale with strong and weak HBs highlighted. (Reproduced from Ref. 35. (C) Royal Society of Chemistry, 2008.)

shift is directly correlated with the length and the strength of the $\mathrm{HB} .{ }^{36}$

Moreover, the ${ }^{1} \mathrm{H}$ chemical shift is very sensitive to the location of the hydrogen atom in these interactions. Direct relationships between $\delta^{1} \mathrm{H}$ and $\mathrm{HB}$ strength and between $\delta^{1} \mathrm{H}$ and $\mathrm{X}-\mathrm{H}$ distance for different classes of hydrogenbonded compounds have been reported. ${ }^{37}$

Thus, NMR shift data can be used to detect and to estimate the presence and the strength of HBs (Scheme 1).

For instance, the HB strength in adducts between dicarboxylic acids and diamine 1,4-diazabicyclo-[2.2.2]octane (DABCO) have been evaluated as a function of the acid chain lengh, that is, of the $\mathrm{p} K_{\mathrm{a}}$. For these compounds it has been shown that intra- and intermolecular $\mathrm{O}-\mathrm{H} \cdots \mathrm{O}$ or $\mathrm{N} \cdot \mathrm{H}-\mathrm{O} \mathrm{HBs}$ are strong interactions with proton chemical shifts of around $16 \pm 1.5 \mathrm{ppm}$, while weaker $\mathrm{N}^{+}-\mathrm{H} \cdots \mathrm{O}^{-}$interactions are characterized by a $\delta^{1} \mathrm{H}$ of about 12.3 ppm. ${ }^{1,37}$

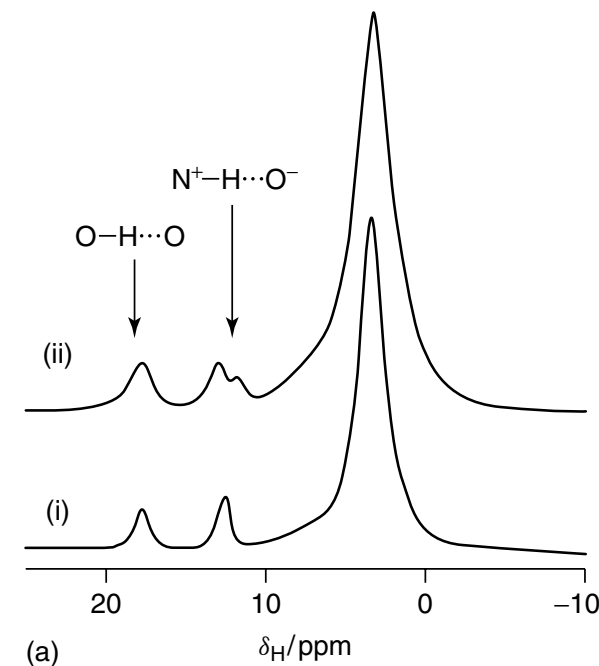

The ${ }^{1} \mathrm{H}$ spectrum of the adduct between malonic acid and DABCO, reported in Figure 4(a), clearly shows in the high frequency region two well defined HB signals at 17.6 and $12.4 \mathrm{ppm}$ that can be assigned to the $\mathrm{O}-\mathrm{H} \cdots \mathrm{O}$ and the $\mathrm{N}^{+}-\mathrm{H} \cdots \mathrm{O}^{-}$protons, respectively (Figure $4 \mathrm{~b}$ ). ${ }^{37}$

Owing to the intrinsic difficulty of $\mathrm{X}$-ray techniques in detecting the hydrogen atom position, an effective method that combines ${ }^{1} \mathrm{H}$ fast MAS NMR and density functional theory (DFT) calculation for the determination of the $\mathrm{O}-\mathrm{H}$ distance has been proposed. ${ }^{38}$ It consists in refining the hydrogen atom position within the $\mathrm{HB}$, in which the computed ${ }^{1} \mathrm{H} \delta$ are reported as a function of the $\mathrm{O}-\mathrm{H}$ distance while all other atoms are retained at their positions. Using the experimental $\delta$ value of $16.5 \mathrm{ppm}$ (Figure 5a), the plot for the succinic acid-DABCO adduct (Figure 5b) gives an $\mathrm{O}-\mathrm{H}$ distance of $1.043 \AA$, which is in good agreement with the value obtained by geometry optimization $(1.039 \AA) .{ }^{37}$

The ${ }^{1} \mathrm{H}$ chemical shift is not the only NMR parameter that can provide insights in $\mathrm{HB}$ interactions but also the ${ }^{13} \mathrm{C} \mathrm{CSA}$ and the ${ }^{15} \mathrm{~N}$ chemical shift are often used.

Nuclear ${ }^{13} \mathrm{C}$-NMR shielding tensors of carboxylic groups significantly change with the protonation state of the group, that is, carboxylic or carboxylate form. ${ }^{39,40}$ For example, the carbon chemical shift tensors of the $\mathrm{COOH}$ signal obtained by sideband analyses of low speed spinning spectra in supramolecular adducts $\left[\mathrm{N}\left(\mathrm{CH}_{2} \mathrm{CH}_{2}\right)_{3} \mathrm{~N}\right]-\mathrm{H}-$ [OOC $\left.\left(\mathrm{CH}_{2}\right)_{n} \mathrm{COOH}\right](n=1-7)^{41}$ afforded information on the character of the $\mathrm{COOH}$ group. $\delta_{33}$ is usually not very sensitive to the protonation state of the carboxylic group, whereas $\delta_{\text {iso }}$ increases in shielding upon protonation, but unfortunately the information is limited by the fact that $\delta_{11}$

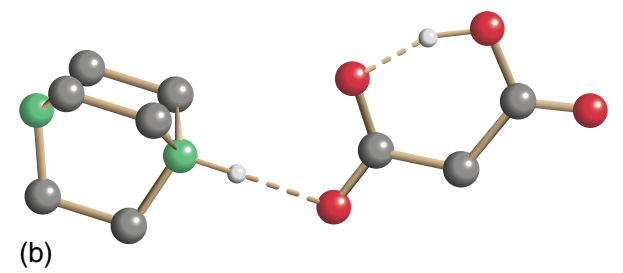

Figure 4 (a) ${ }^{1} \mathrm{H}$ MAS NMR spectrum $\left(\omega_{r}=35 \mathrm{kHz}\right)$ of the adduct between malonic acid and DABCO obtained at $500 \mathrm{MHz}$ (i) and at $300 \mathrm{MHz}$ (ii). The different shape of the $\mathrm{N}^{+}-\mathrm{H} \cdots \mathrm{O}^{-}$signal is due to second order quadrupolar effect of the ${ }^{14} \mathrm{~N}$ nucleus on the ${ }^{1} \mathrm{H}$ spectrum that is magnetic field dependent. (b) Single-crystal X-ray structure of the malonic acid-DABCO adduct. (Reproduced from Ref. 37. (C) American Chemical Society, 2005.) 

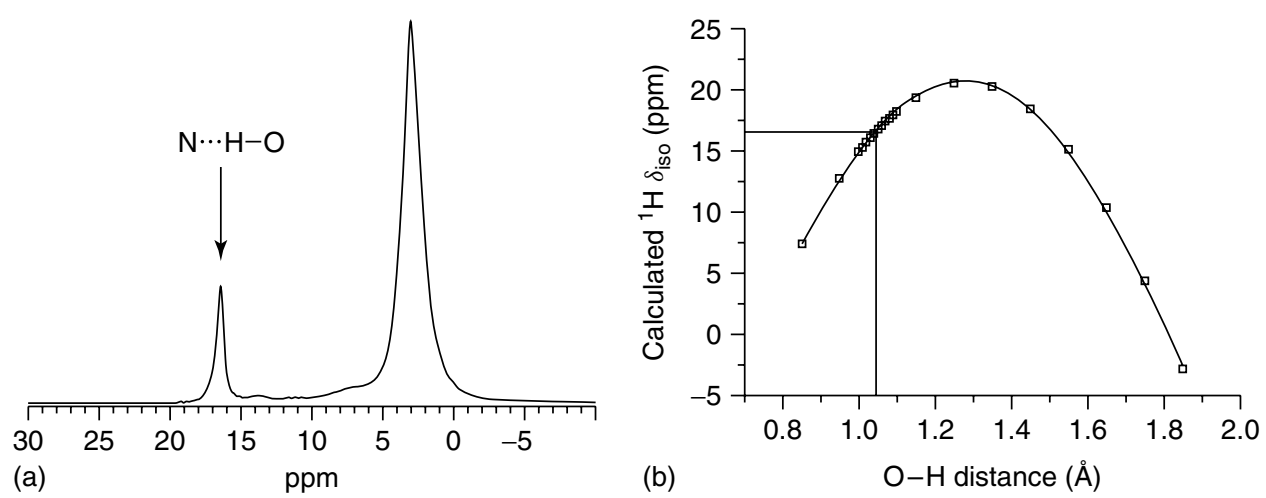

Figure 5 (a) ${ }^{1} \mathrm{H}$ MAS NMR spectrum $\left(500 \mathrm{MHz}, \omega_{r}=35 \mathrm{kHz}\right)$ of the adduct between succinic acid and DABCO. (b) Plot of the calculated ${ }^{1} \mathrm{H}$ chemical shift versus the $\mathrm{O}-\mathrm{H}$ distance in which the experimental ${ }^{1} \mathrm{H}$ chemical shift has been used in order to obtain a reliable O-H distance. (Reproduced from Ref. 37. (C) American Chemical Society, 2005.)

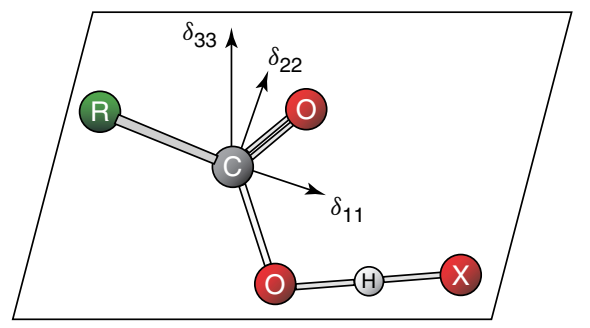

(a)

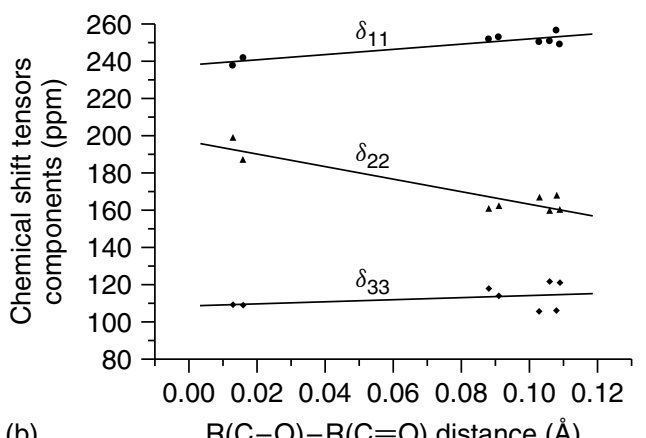

(b)

$\mathrm{R}(\mathrm{C}-\mathrm{O})-\mathrm{R}(\mathrm{C}=\mathrm{O})$ distance $(\AA)$

Figure 6 (a) Orientation of chemical shift tensors $\left(\delta_{11}, \delta_{22}\right.$, and $\left.\delta_{33}\right)$ in carboxylic groups. (b) Chemical shift tensors versus difference between $\mathrm{C}-\mathrm{O}$ and $\mathrm{C}=\mathrm{O}$ bond lenghts for dicarboxylic acid-DABCO adducts. (Reproduced from Ref. 41. (C) Wiley-VCH, 2003.)

and $\delta_{22}$ change their values in opposite direction. $\delta_{22}$, the chemical shift tensor that lies perpendicular to the plane of symmetry of the $\mathrm{C}=\mathrm{O}$ group, is the most diagnostic parameter that reflects the $\mathrm{HB}$ strength (Figure 6).

On the other hand, ${ }^{15} \mathrm{~N}$ chemical shifts are very sensitive to the protonation state of the nitrogen involved in the $\mathrm{HB}$ interaction due to the wider range of chemical shift with respect to ${ }^{13} \mathrm{C}$ : intermolecular $\mathrm{HBs}$ produce a high frequency or low frequency shift in the ${ }^{15} \mathrm{~N}$ values according to the type of nitrogen atom and to the type of synthons involved (Scheme 2). ${ }^{42}$

The diagnostic value of the ${ }^{15} \mathrm{~N}$ chemical shifts has been demonstrated by exploring the effects of acid-base interactions on the ${ }^{15} \mathrm{~N}$ spectra in dry solid poly-L-lisine with different acids. ${ }^{43}$

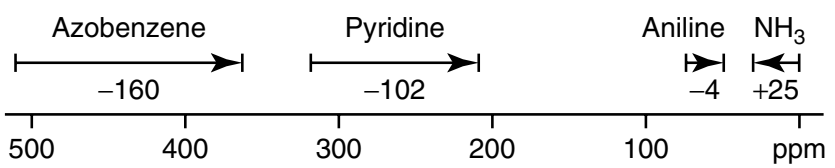

Scheme 2 Influence of HBs on the ${ }^{15} \mathrm{~N}$ chemical shift of some nitrogen-containing group.
Combined experimental and computational (DFT) results reveal low-field shifts of the amino nitrogen upon interaction with $\mathrm{HX}$ acids $\left(\mathrm{HX}=\mathrm{HF}, \mathrm{H}_{2} \mathrm{SO}_{4}, \mathrm{CF}_{3} \mathrm{COOH}\right.$, $\left(\mathrm{CH}_{3}\right)_{2} \mathrm{POOH} \mathrm{H}_{3} \mathrm{PO}_{4}$, and $\left.\mathrm{HNO}_{3}\right) .{ }^{15} \mathrm{~N}$ chemical shifts are maxima when the hydrogen is located in the $\mathrm{HB}$ center and then decrease again upon full protonation (as found also for aqueous solution at low $\mathrm{pH}$ ). The combined use of ${ }^{1} \mathrm{H}$ and ${ }^{15} \mathrm{~N}$ chemical shift data allows a distinction to be made between $\mathrm{N}^{+}-\mathrm{H} \cdots \mathrm{O}^{-}$interactions (with proton transfer) and $\mathrm{N} \cdot \mathrm{H}-\mathrm{O}$ interactions (without proton transfer) and between strong and weak HBs. Correlation of the isotropic ${ }^{15} \mathrm{~N}$ chemical shift with the internuclear distances of the heavier atoms ( $\mathrm{N}-\mathrm{O}$ distance) involved in the $\mathrm{HB}$ interaction has been ascertained in the adducts of formula $\left[\mathrm{N}\left(\mathrm{CH}_{2} \mathrm{CH}_{2}\right)_{3} \mathrm{~N}\right]-\mathrm{H}-\left[\mathrm{OOC}\left(\mathrm{CH}_{2}\right)_{n} \mathrm{COOH}\right](n=1-7)$ (Figure 7). ${ }^{41}$

By comparing ${ }^{13} \mathrm{C}$ chemical shift and CSA and ${ }^{15} \mathrm{~N}$ chemical shift data it has been demonstrated that it is possible to evaluate the cocrystal or salt character of an adduct.

An other case is the supramolecular complex 1,10dipyridylferrocene-anthranilic acid $\left\{\left[\mathrm{Fe}\left(\eta^{5}-\mathrm{C}_{5} \mathrm{H}_{4}-\mathrm{C}_{5} \mathrm{H}_{4} \mathrm{~N}\right)_{2}\right]-\right.$ $\left.\left[\left(\mathrm{C}_{6} \mathrm{H}_{4}\right) \mathrm{NH}_{2} \mathrm{COOH}\right]\right\}_{2}$. The comparison of the free pyridine nitrogen chemical shift with that of the pyridine nitrogen 


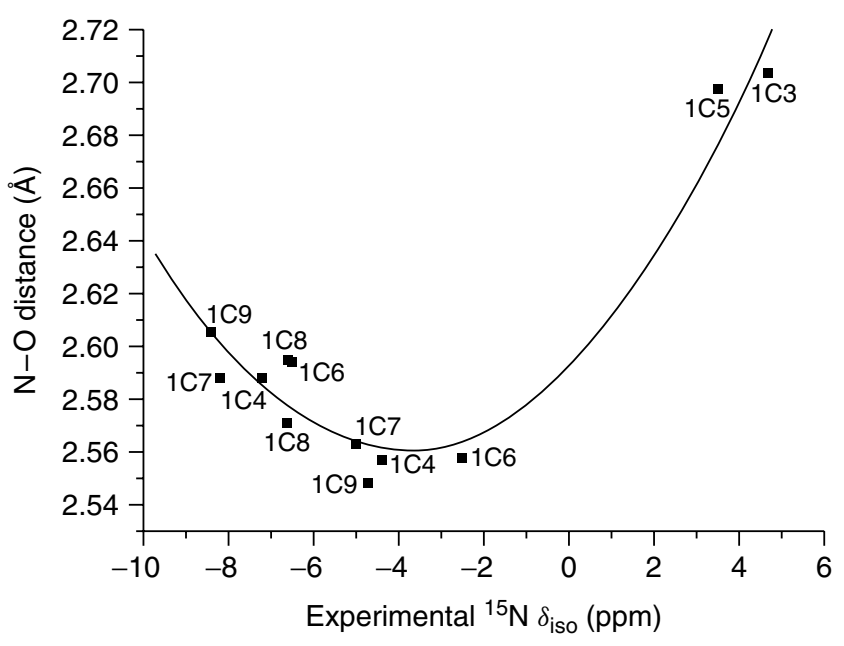

Figure 7 Plot of the experimental ${ }^{15} \mathrm{~N}$ chemical shift of the nitrogen atoms involved in $\mathrm{HB}$ versus the $\mathrm{N}-\mathrm{O}$ distance for dicarboxylic acid-DABCO adducts. (Reproduced from Ref. 41. (c) Wiley-VCH, 2003.)

in the adduct resulted in the confirmation of the presence of a strong $\mathrm{O}-\mathrm{H} \cdots \mathrm{N}$ interaction with no proton transfer from the acid to the nitrogen base and of a weak $\mathrm{N}-\mathrm{H} \cdots \mathrm{N}$ interaction. $^{44}$

In the $\mathrm{HB}$ characterization 1D spectra give information concerning the HB presence, the hydrogen-bonded atom position, and the strengh of the interaction, while $2 \mathrm{D}{ }^{1} \mathrm{H} \mathrm{DQ}$ MAS experiments provide elucidation of $\mathrm{HB}$ geometries and networks.

This is the case of the three crystal forms of the cocrystal 4,4'-bipy/pimelic acid (bipy $=$ bipyridine), $\left[\mathrm{NH}_{4} \mathrm{C}_{5}{ }^{-}\right.$ $\left.\mathrm{C}_{5} \mathrm{H}_{4} \mathrm{~N}\right]-\left[\mathrm{HOOC}\left(\mathrm{CH}_{2}\right)_{5} \mathrm{COOH}\right]$, where their relationship have been investigated by comparing single-crystal X-ray diffraction and ${ }^{1} \mathrm{H}$ DQ MAS SSNMR experiments. ${ }^{5} \mathrm{X}-$ ray diffraction supplied packing and conformation of the molecules while ${ }^{1} \mathrm{H}$ DQ MAS spectra provided new parameters for differencing the polymorphs and for elucidating the HB network.

In another case rotor-synchronized ${ }^{1} \mathrm{H}$ DQ MAS spectra were used to elucidate the supramolecular structures adopted by two different alkyl-substituted benzoxazine dimers [ $N, N$-bis(3,5-dimethyl-2-hydroxybenzyl) "R" amine], where "R" = methyl or ethyl. ${ }^{4}$

Figure 8 shows the $1 \mathrm{D}$ and $2 \mathrm{D}{ }^{1} \mathrm{H}(500.1 \mathrm{MHz}) \mathrm{MAS}$ $\left(\omega_{\mathrm{r}}=35 \mathrm{kHz}\right)$ spectra of the methyl (solid line) and ethyl (dashed line) dimers together with their HB network. Of most importance are the clear differences between the two spectra in the HB region. The analysis of the DQ signals in the $2 \mathrm{D}{ }^{1} \mathrm{H}$ DQ MAS experiments allowed to establish that the methyl and the ethyl compounds are arranged in dimers and chains, respectively, as elucidate in Figure 8(d) and (e).

\subsection{Distances and constrains determined by solid-state NMR}

As already said, many applications of SSNMR for structure determination rely upon the dependence of the dipolar coupling on $1 / r_{\text {IS }}^{3}$ where $r_{\text {IS }}$ is the distance between the two spins $I$ and $S$.

All these techniques provide distances which compare very well with those obtained by X-ray diffraction (XRD) if the samples contain isolated spin pairs (typically $\pm 0.05 \mathrm{~nm}$ and often better). Spiess, Schnell, and coworkers ${ }^{45}$ were able to demonstrate the potential of the combined use of advanced SSNMR pulse sequences, (HDOR, heteronuclear dipolar-order rotor encoding and REREDOR, rotor-encoded REDOR), and quantum-chemical calculations for investigating the multiple HB network of $N$-butylaminocarboxyl6 -tridecylisocitosine in the pyrimidone and pyrimidinol forms (Scheme 3).

By performing solid-state ${ }^{1} \mathrm{H}-{ }^{15} \mathrm{~N}$ dipolar recoupling experiments, the authors were able to providing $\mathrm{N}-\mathrm{H}$ distances of up to about $250 \mathrm{pm}$ with an accuracy level of $\pm 1 \mathrm{pm}$ for short distances (around $100 \mathrm{pm}$ ) and $\pm 5 \mathrm{pm}$ for longer distances (180-250 pm). Also vibrational effects have been taken into account and the zero-point vibrations were found to enlarge the apparent distance determined for a typical $\mathrm{N}-\mathrm{H}$ bond $(103.5 \mathrm{pm})$ by about $3 \mathrm{pm}$.

However, in most cases, where multiple spin systems are present and the number of spins and/or their geometrical arrangement is completely unknown is highly unlikely that reliable distances can be directly obtained from REDOR measurements. Furthermore the technique is complicated by rapid motion of the molecular structure. This is the case, for example, of the distance evaluation of the intermolecular distance between host and guest molecular components in supramolecular compounds such as $p$-tertbutylcalix(4)arene fluorobenzene where the ${ }^{13} \mathrm{C}$ NMR signal is modulated by heteronuclear dipolar interaction with the ${ }^{19} \mathrm{~F}$ containing guest in redox experiments. ${ }^{46}$

A recent review from Brown ${ }^{22}$ elegantly collects some examples of the use of SEDOR (spin-echo double resonance), REDOR, and REAPDOR techniques for the determination of ${ }^{13} \mathrm{C}-{ }^{17} \mathrm{O}$ and ${ }^{15} \mathrm{~N}-{ }^{17} \mathrm{O}$ dipolar couplings. ${ }^{47}$ However, these represent rare cases since for the oxygen atom there is only one NMR active isotope, oxygen17 , which has a natural abundance of $0.038 \%$ and is a spin $I=5 / 2$. Thus its study absolutely requires isotopic enrichment.

Concerning the opportunities offered by constrain measurements through 2D SSNMR it is worth spending some words about their application in the biological fields. Indeed the number of articles devoted to the supramolecular structure elucidation by means of SSNMR of biocompounds is increasing. ${ }^{48}$ Like its liquid-state analogue, SSNMR 


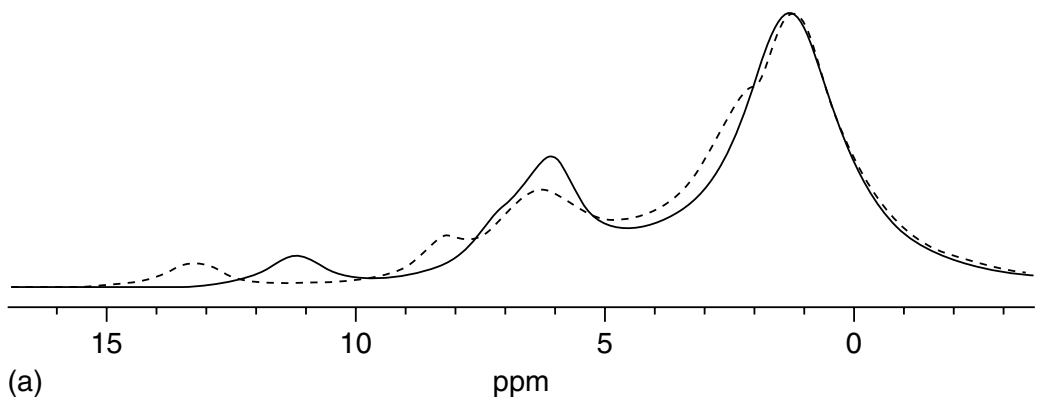

(a)

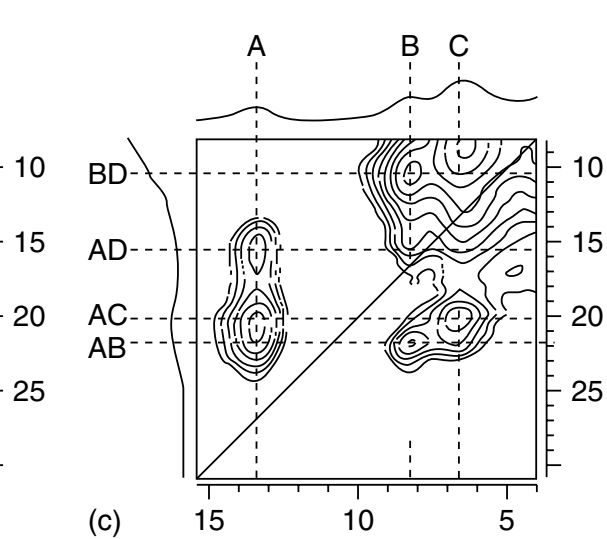

(b)

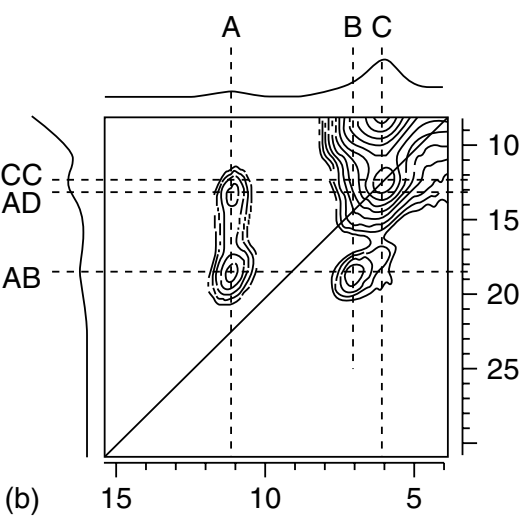

(c)

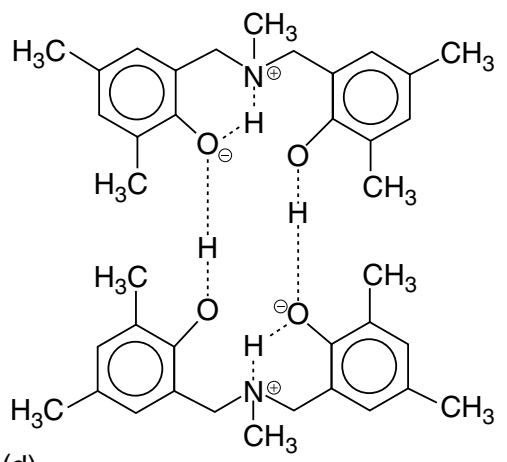

(d)

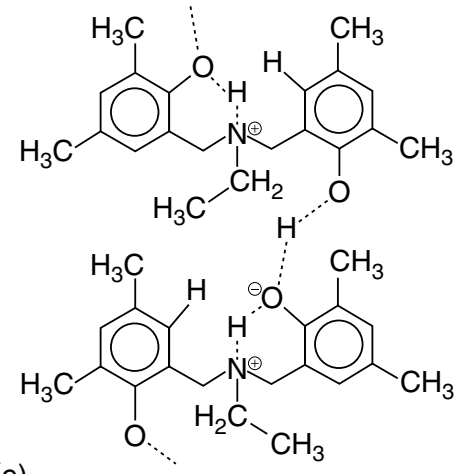

(e)

Figure 8 (a) ${ }^{1} \mathrm{H}$ MAS spectra $\left(500 \mathrm{MHz}, \omega_{r}=35 \mathrm{kHz}\right)$ of the methyl (solid line) and ethyl (dashed line) benzoxazine compounds. (b, c) HB regions of ${ }^{1} \mathrm{H}$ DQ MAS spectra of the methyl (b) and ethyl (c) b compounds. (d, e) Schematic arrangement of the dimer (methyl) and chain-like (ethyl) structure. (Reproduced from Ref. 4. (c) American Chemical Society, 1998.)

spectroscopy does not automatically provide long-range structure-symmetry information as known from X-ray crystallography. As a consequence, large amounts of data on several differently labeled samples have typically been required to obtain sufficient long-range information. These requirements in some way have limited its diffusion. However, it has been demonstrate ${ }^{49}$ that it is possibile to identify the supramolecular conformation of fibrils directly from symmetry-induced resonance patterns in 2D heteronuclear ${ }^{15} \mathrm{~N}-{ }^{13} \mathrm{C}{ }^{\mathrm{OC}} \mathrm{NCO}$ and ${ }^{15} \mathrm{~N}-{ }^{13} \mathrm{C}{ }^{\mathrm{OC}} \mathrm{NCA}$ (superscript OC designates experiments ${ }^{50}$ designed using optimal control theory) correlation and homonuclear ${ }^{13} \mathrm{C}^{\prime}-{ }^{13} \mathrm{C} \alpha$ DARR ${ }^{51}$ correlation SSNMR spectra for a single ${ }^{13} \mathrm{C},{ }^{15} \mathrm{~N}$-labeled hIAPP20-29 (SNNFGAILSS) decapeptide from the human islet amyloid polypeptide (hIAPP), which is believed to form the fibrillation core domain of fibrils in the pancreas of type 2 diabetes patients. Again, several types of oneand two-dimensional SSNMR techniques have been used to obtain constraints on the peptide conformation and supramolecular structure in amylin fibrils, a 37-residue peptide also called islet amyloid polypeptide or IAPP, and to derive molecular structural models that are consistent with the experimental data. ${ }^{52}$

SSNMR measurements on a series of isotopically labeled samples indicate a single molecular structure within the striated ribbons which contains four layers of parallel $\beta$-sheets, formed by two symmetric layers of amylin molecules. 


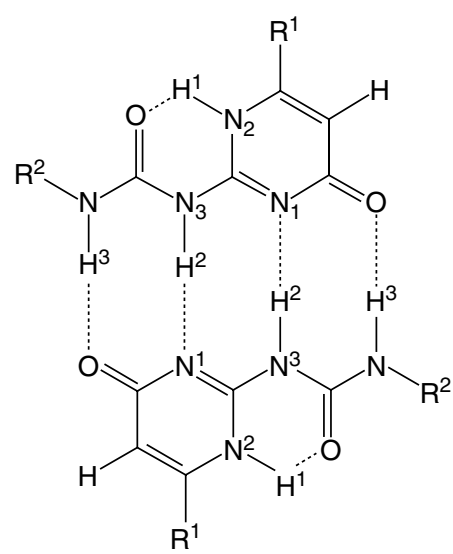

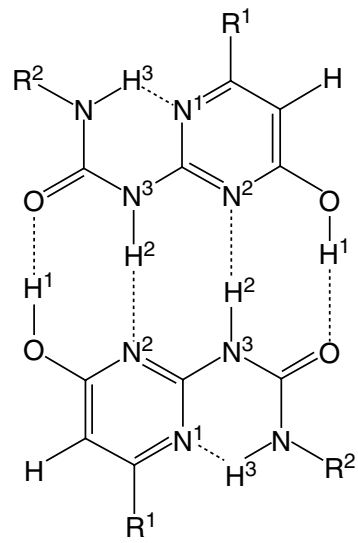

1: $\mathrm{R}^{1}=n-\mathrm{C}_{13} \mathrm{H}_{27}, \mathrm{R}^{2}=n-\mathrm{C}_{4} \mathrm{H}_{9}$ $1^{\prime}: \mathrm{R}^{1}=\mathrm{CH}_{3}, \mathrm{R}^{2}=\mathrm{CH}_{3}$

(a)

2: $\mathrm{R}^{1}=n-\mathrm{C}_{13} \mathrm{H}_{27}, \mathrm{R}^{2}=n-\mathrm{C}_{4} \mathrm{H}_{9}$ 2': $\mathrm{R}^{1}=\mathrm{CH}_{3}, \mathrm{R}^{2}=\mathrm{CH}_{3}$

(b)

Scheme 3 Schematic representation with HB network of the $\mathrm{N}$-butylaminocarboxyl-6-tridecylisocitosine in the pyrimidone (a) and pyrimidinol (b) forms. (Reproduced from Ref. 45. (C) Wiley-VCH, 2005.)

\section{$3.3 \pi-\pi$ interactions}

Although much less strong than hydrogen bonding, aromatic $\pi-\pi$ interactions and ring-current effects associated with the presence of aromatic moieties represent an other important source of structural information. In the last two decades $\pi$-stacking interactions between aromatic systems have been extensively studied. This interaction has been proposed to be a pivotal assembly force in many important supramolecular systems including various protein and enzyme substrates, ${ }^{53}$ nucleic acids, ${ }^{54}$ and molecular catalysts. ${ }^{55}$

A deeper understanding of the nature of the interaction is the key step for developing the synthesis of controlled nanoscale structures.

Intra- or intermolecular ring currents due to nearby through-space aromatic moieties produce variation of the NMR chemical shift in "exposed" part of the molecule. Although all the nuclei are sensitive to this kind of effects, the main application are found for high-resolution ${ }^{1} \mathrm{H}$ solid-state spectra since a more pronounced effect can be visualized on the small chemical shift range of the proton nucleus. A clear example of ring-current effects in ${ }^{1} \mathrm{H}$ MAS SSNMR has been reported by Brown, Spiess, and coworkers ${ }^{56}$ in the study of the host-guest interaction between naphthalene-spaced tweezer as host molecule and 1,4-dicyanobenzene, as aromatic, electron-deficient guest (Figure 9).

In $\mathrm{CDCl}_{3}$ solution formation and dissociation processes occur in the NMR timescale at room temperature and the aromatic protons are shown as a single resonance in the

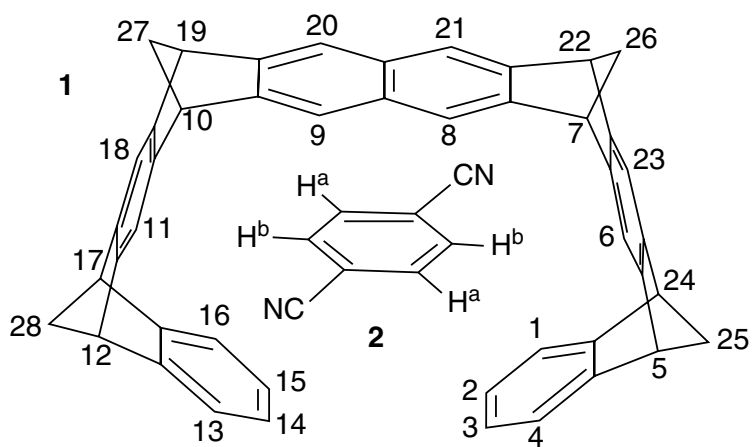

Figure 9 Schematic representation of the naphthalene-spaced tweezer-1,4-dicyanobenzene host-guest complex. (Reproduced from Ref. 56. (C) Wiley-VCH, 2001.)

${ }^{1} \mathrm{H}$ solution NMR spectrum, shifted by $4.35 \mathrm{ppm}$ relative to that observed for the guest molecule alone. X-ray structure shows that the two guest aromatic protons $\mathrm{H}^{\mathrm{a}}$ and $\mathrm{H}^{\mathrm{b}}$ are differently involved in the ring currents due to the host molecule, with a distance of $\mathrm{H}^{\mathrm{b}}$ to the center of inner benzene ring of only $260 \mathrm{pm}$. SSNMR investigation reveals that the guest remains complexed on the time scale of the NMR experiment. Accordingly a large difference in the proton chemical shift $\left(\mathrm{H}^{\mathrm{a}}=5.6 \mathrm{ppm}, \mathrm{H}^{\mathrm{b}}=2.0 \mathrm{ppm}\right)$ have been detected as shown in the rotor syncronized ${ }^{1} \mathrm{H}$ DQ MAS NMR spectrum (Figure 10). Such splitting, that is not present in solution, is a strong indication of ring-current effects.

All the NMR data are strongly supported by combining a theoretical approach by performing quantumchemical calculations to determine the structure and NMR chemical shifts of the host-guest complex. The approach presented by these authors clearly exploits the sensitivity of ${ }^{1} \mathrm{H}$ chemical shift to aromatic ring currents and can be in principle applied to crystalline and amorphous systems.

A interesting example of the importance of ring-current effects in ${ }^{1} \mathrm{H}$ SSNMR is provided by the polycyclic aromatic molecule, hexa- $n$-dodecylhexa dodecylhexa-perihexabenzocoronene. ${ }^{57}$ By means of the ${ }^{1} \mathrm{H}$ MAS spectrum, in which three distinct aromatic resonances are identified (Figure 11a), it has been shown that hexa- $n$ dodecylhexa dodecylhexa-peri-hexabenzocoronene forms a columnar mesophase with a very high one-dimensional charge carrier mobility. The observation of these distinct aromatic resonances is explained in terms of the differing degrees to which the aromatic protons experience the ring current of adjacent layers. Using the rotor-synchronized DQ MAS method (Figure 11b), definite proton-proton proximities are identified, which are shown to be in agreement with the known crystal structure of unsubstituted hexabenzocoronenes (Figure 12). 

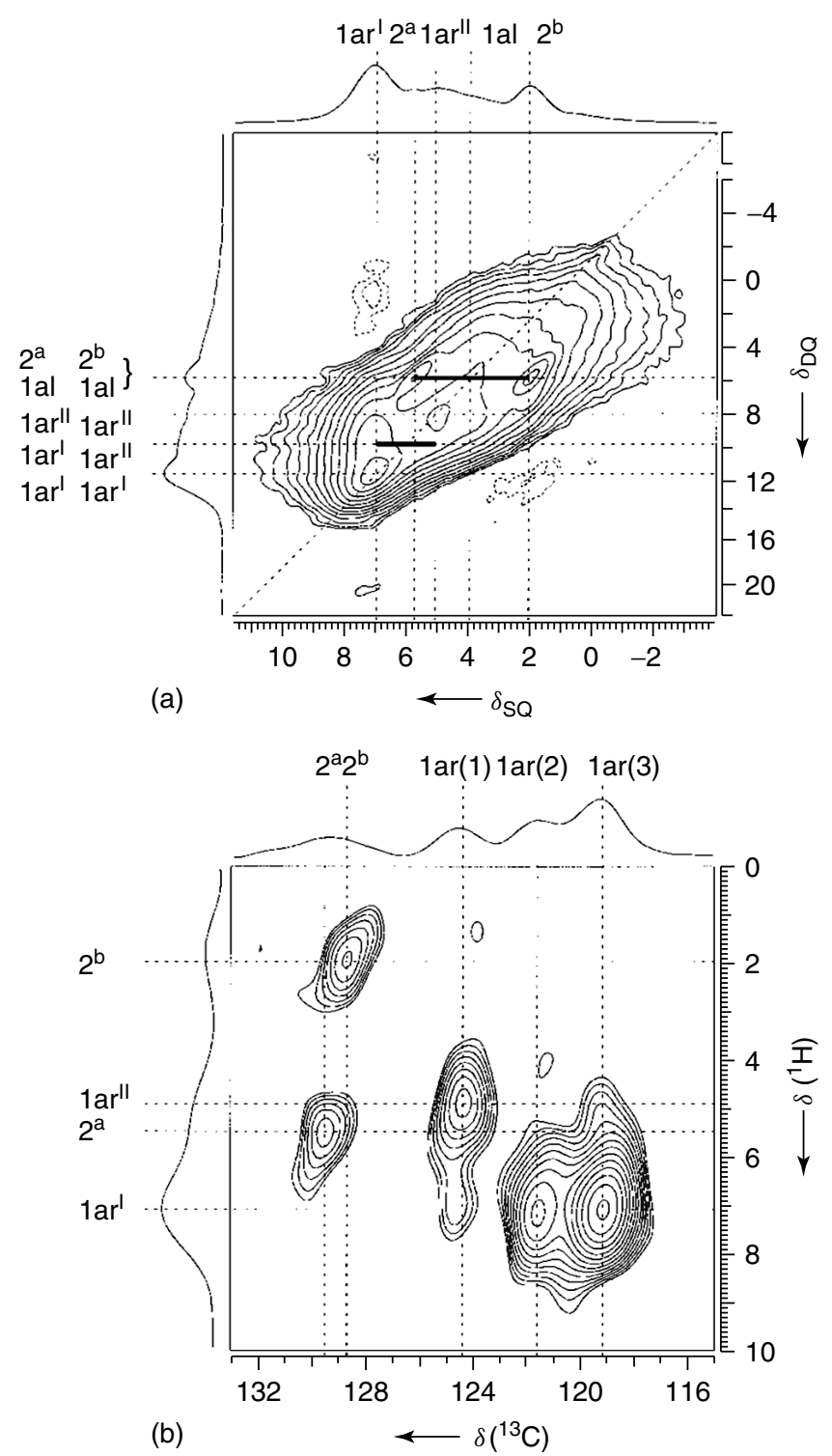

Figure 10 (a) Rotor-synchronized ${ }^{1} \mathrm{H}$ DQ MAS spectrum $\left(700 \mathrm{MHz}, \omega_{r}=30 \mathrm{kHz}\right)$ of the naphthalene-spaced tweezer-1,4dicyanobenzene host-guest complex. (b) ${ }^{1} \mathrm{H}-{ }^{13} \mathrm{C}$ REPT-HSQC NMR correlation spectrum of the naphthalene-spaced tweezer1,4-dicyanobenzene host-guest complex. The notation 1 ar and 1 al refers to host aromatic and alkyl protons, respectively, while $2^{\mathrm{a}}$ and $2^{\mathrm{b}}$ to the two distinct guest aromatic protons. (Reproduced from Ref. 56. (c) Wiley-VCH, 2001.)

\section{DYNAMICS IN SUPRAMOLECULAR SYSTEMS}

The possibility of dynamic behavior for single groups or entire molecules in the solid state when weak noncovalent interatomic forces are present is quite general and this phenomenon has a pronounced influence on the macroscopic physical properties of the supramolecular systems. ${ }^{22}$
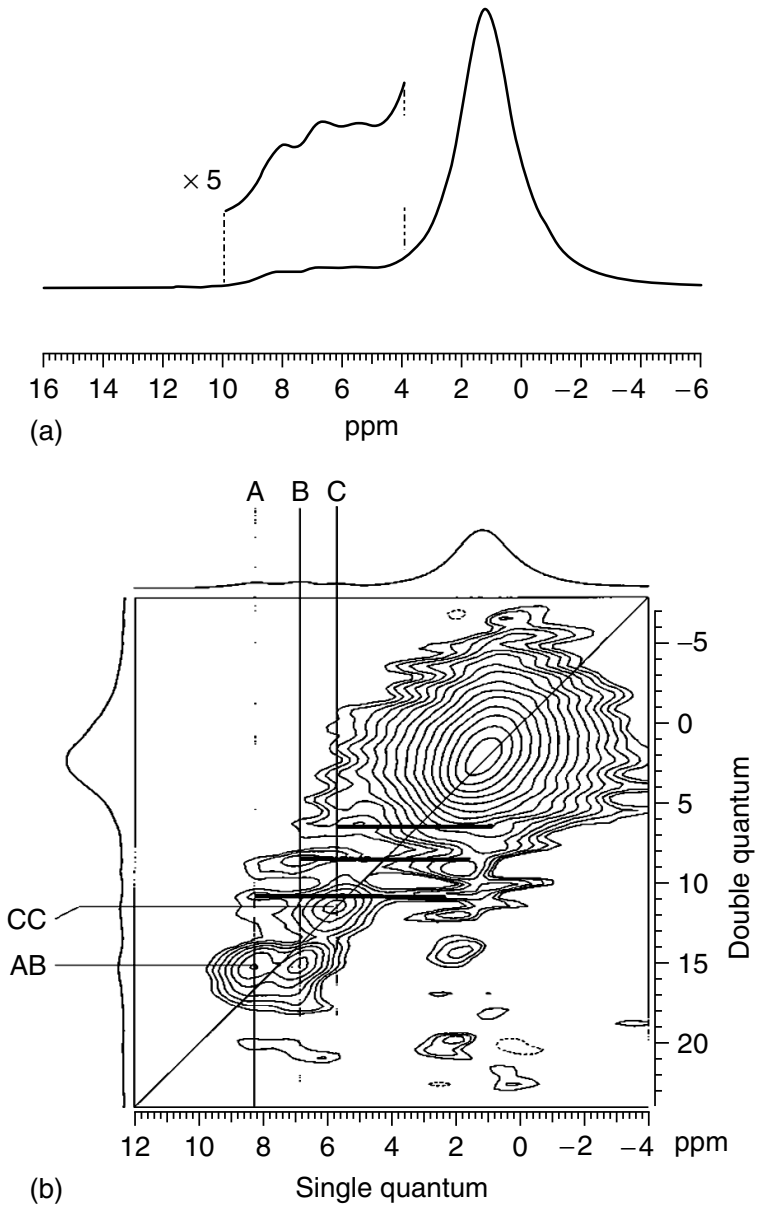

Figure 11 (a) ${ }^{1} \mathrm{H}$ MAS $\left(500 \mathrm{MHz}, \omega_{r}=35 \mathrm{kHz}\right)$ spectrum and (b) rotor-synchronized ${ }^{1} \mathrm{H}$ DQ MAS NMR spectrum of hexa- $n$ dodecylhexa dodecylhexa-peri-hexabenzocoronene. (Reproduced from Ref. 57. (c) American Chemical Society, 1999.)

This is typical, for example, of host-guest adducts, where lower activation energy barriers are expected for the motion of molecules within the cavity or the channel of a matrix. These motions can cover a wide range of correlation times from very fast processes that occur in nanoseconds down to very slow motions of the order of seconds. ${ }^{58}$

Since the aim of the dynamic investigation is the quantification of the time scale of the motion and the geometric interpretation of the molecular process, the type and the correlation time of dynamics determine the choice of experiments and techniques. The SSNMR represents a powerful tool for the investigation of molecular dynamics due to the possibility offered by the use of different parameters to cover a wide timescale of a fluxional process from $10^{2}$ to $10^{-10} \mathrm{~s}$. When the motion occurs it determines variations in the NMR spectra that are dependent from the strength of the interaction tensors, the correlation time of the motion and the orientation of the interaction tensors 


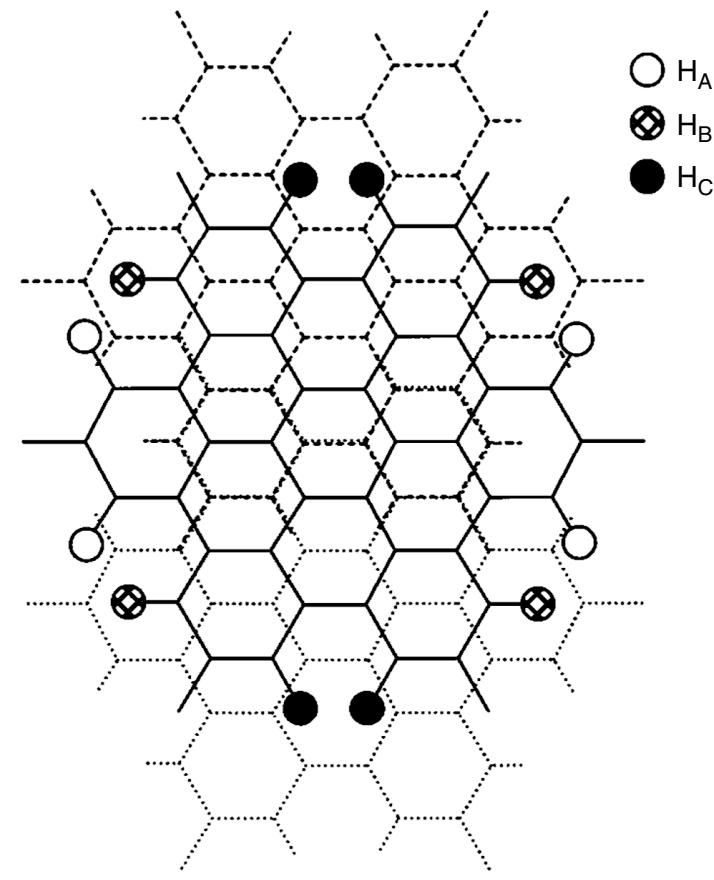

Figure 12 Representation of the proposed stacking of the aromatic cores in hexa- $n$-dodecylhexa dodecylhexa-perihexabenzocoronene. Three molecules are shown; the molecules above and below the central molecule are indicated by dashed and dotted lines, respectively. (Reproduced from Ref. 57. (C) American Chemical Society, 1999.)

with respect to the external magnetic field. Several SSNMR experiments in low resolution (wideline) and high resolution (lineshape analysis at VT, CSA analysis, 2D-EXSY, relaxation time studies, etc.) are able for detecting and quantifying molecular motions involving individual groups or entire molecules.

Spin-lattice relaxation time $\left(\mathrm{T}_{1}\right)$ measurements obtained by inversion recovery or saturation recovery ${ }^{59}$ have been used to investigate dynamic processes of the order of microseconds, whereas slower motions can be tackled by relaxation time in the rotating frame, $\mathrm{T}_{1 \rho} \cdot{ }^{60} \mathrm{In}$ this case relaxation measurements are related to the spin lock field of the order of tens of kilohertz, allowing the extension of dynamic studies to lower frequencies. Alternatively by means of $\mathrm{CP}$ pulses, dynamic information can be achieved by heteronuclear $T_{1 \rho}$ measurements. ${ }^{61}$ Further available methods are the measurement of relaxation parameters such as heteronuclear $\mathrm{T}_{1}$, heteronuclear $\mathrm{T}_{1 \rho}, \mathrm{X}-\mathrm{H}$ crossrelaxation time and proton relaxation time in the dipolar state $\left(\mathrm{T}_{1 D}\right){ }^{62}$

In Scheme 4 the relationship between the correlation time for a molecular motion and NMR parameters is reported.

Deuteron NMR has been long known as a powerful tool for probing molecular dynamics. ${ }^{63}$

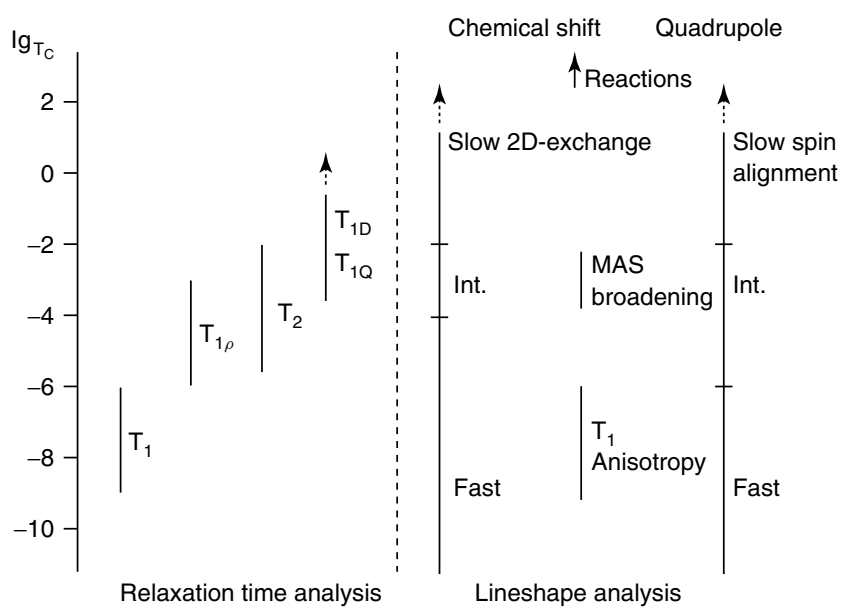

Scheme 4 Schematic representation of the correlation time range covered by the NMR parameters.

Isotopic substitution in a supramolecular system enables site-selective investigation of dynamics. For example, substitution of protons atoms with deuterium atoms allows the use of VT low resolution ${ }^{2} \mathrm{D}$ NMR investigation where the motionally induced reorientation of the ${ }^{2} \mathrm{H}$ quadrupolar tensor will affect intensities and linewidths of the ${ }^{2} \mathrm{D}$ spectra. Deuteron NMR line shapes and relaxation rates are usually dominated by the interaction of the nuclear electric quadrupole moment with the electric field gradient at the site of the nucleus. The deuteron has a relatively small electric quadrupole moment, which makes it easy to work with experimentally. Available deuteron NMR techniques cover a very broad range of time scales, from pico- to milliseconds. 64

The basic formula describing the angular dependent quadrupolar coupling is given by

$$
\omega=\omega_{\mathrm{L}} \pm 0.5 \omega_{\mathrm{Q}}\left(3 \cos ^{2} \theta-1\right) \eta \sin ^{2} \theta \cos ^{2} \phi
$$

where $\omega_{\mathrm{L}}$ is the Larmor frequency and $\omega_{\mathrm{Q}}$ represents the strength of the quadrupolar coupling. The asymmetry parameter $\eta$ describes the deviation from axial symmetry while the angles $\theta$ and $\phi$ are the polar angles of the magnetic field $\mathrm{B}_{\mathrm{o}}$ in the principal axes system of the quadrupolar coupling tensor. For rigid $\mathrm{C}-\mathrm{H}$ bonds, its unique axis is along the $\mathrm{C}-\mathrm{H}$ direction. In a powder, the maximum frequency splitting is then $2 \omega_{\mathrm{Q}}$. However, in the presence of rapid molecular motion, the quadrupolar interaction can be partially averaged, thus yielding an averaged quadrupolar coupling tensor.

Computer fitting of the lineshape based on an assumed model for the dynamic process affords the types as well as the rate constant $\mathrm{k}$ extracted over a range of temperature, allowing the calculation of the activation energy. Though in difficult cases experimental lineshapes may be 
reproduced by several distinct models, ${ }^{65}{ }^{2} \mathrm{H}$ NMR still provides a fairly easy access to local geometries of mobile species.

In the case of MAS conditions, the ${ }^{2} \mathrm{H}$ spectrum has a sufficient resolution to resolve distinct deuteron sites with different chemical shifts and the SSB pattern reflects the envelope of the static quadrupolar lineshapes.

Guest molecules included into cavities created by host molecules such as cyclodextrin (CD), zeolites, alluminosilicates, and so on are often involved in motions with relatively low activation energies. The mobility in a solidstate inclusion environment represents a different dynamic regime in comparison with both solution and crystalline situations. In several cases the rotation of the entire molecule occurs only along certain axis. The shape of the guest, the size of the host and the strength of the host-guest intermolecular forces play a fundamental role in determining the kind of process involved and the regime of the motion.

A typical example of dynamics in supramolecular systems has been reported by Garcia-Garibay and coworkers for MOF-5 that has a cubic framework composed of $\mathrm{Zn}_{4} \mathrm{O}$ clusters (vertices) bridged by $1-4$ phenyldicarboxylates (Figure 13). ${ }^{66}$

Dynamics of phenylene deuterated $\mathrm{d}_{4}-\mathrm{MOF}-5$ have been determined using VT ${ }^{2} \mathrm{H}$ NMR. Spectra at $300 \mathrm{~K}$ shows deuterons in the slow exchange regime, whereas the spectra recorded between 363 and $435 \mathrm{~K}$ are related to the intermediate regime of motion (Figure 14). By fitting the experimental data with a twofold flipping model $\left(180^{\circ}\right.$ rotation), the Arrhenius analysis of the exchange rate affords an activation energy of $11.3 \pm 2.0 \mathrm{Kcal} \mathrm{mol}^{-1}$.
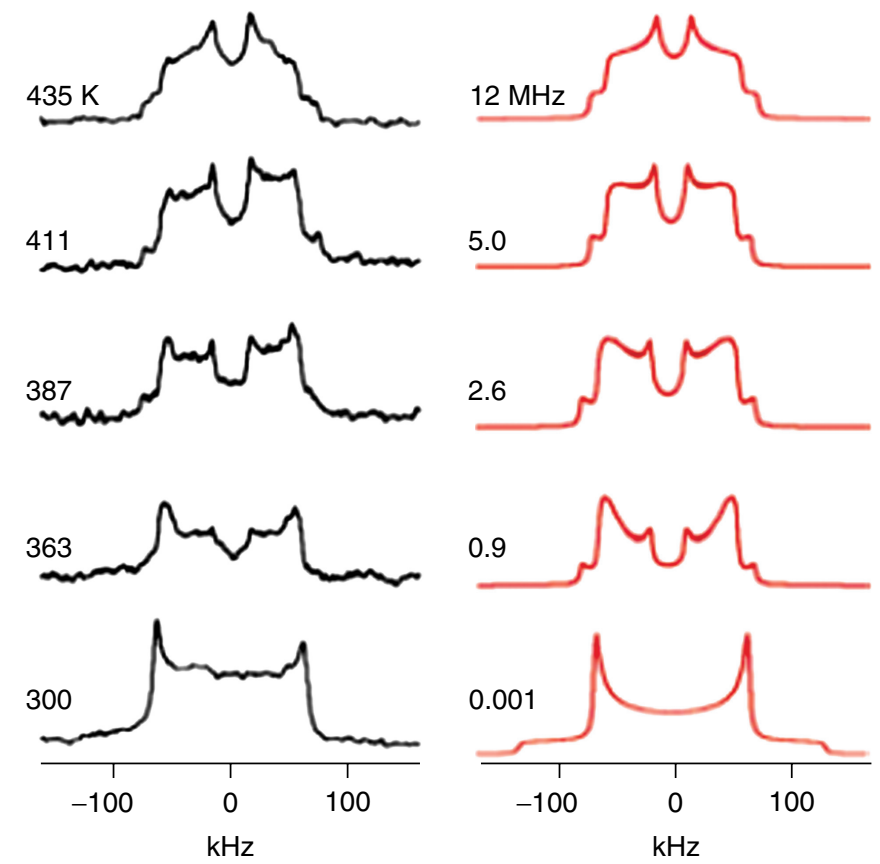

Figure 14 Experimental (left) and calculated (right) quadrupolar echo solid state ${ }^{2} \mathrm{H}$ NMR of phenylene deuterated $\mathrm{d}_{4}-\mathrm{MOF}-5$ sample sealed at 3 mTorr. (Reproduced from Ref. 66. (c) American Chemical Society, 2008.)

Solid-state guest dynamics of dimeric capsules of tetratolyl urea calix[4]arene filled with different aromatic guests such as benzene- $\mathrm{d}_{6}$, fluorobenzene- $\mathrm{d}_{5}$ and 1,4difluorobenzene were studied. Upon inclusion, all guest moieties revealed complexation-induced shifts varying from 2.8 to $5.1 \mathrm{ppm}$. All guest molecules were shown to undergo

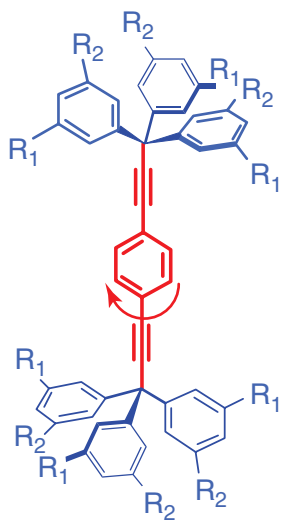

1a: $R_{1}=H, R_{2}=H$

1b: $R_{1}=\mathrm{OCH}_{3}, \mathrm{R}_{2}=\mathrm{H}$

1c: $\mathrm{R}_{1}=t-\mathrm{Bu}, \mathrm{R}_{2}=t-\mathrm{Bu}$

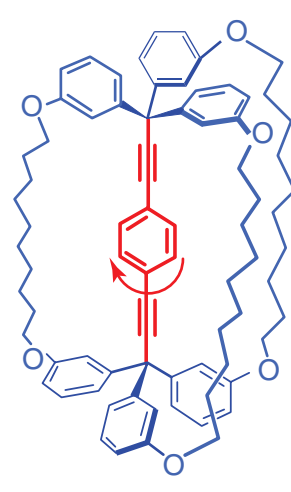

2

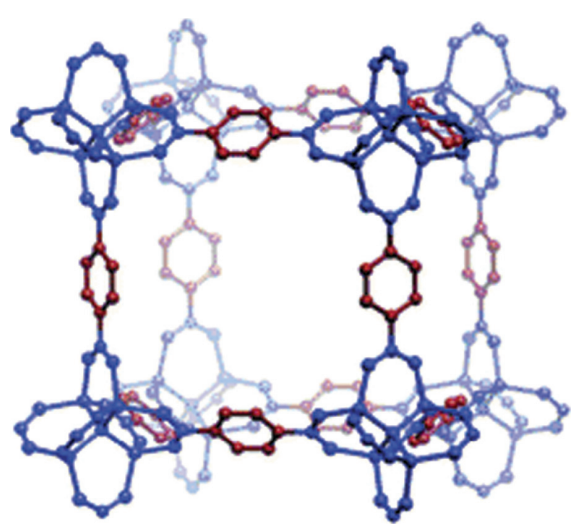

Figure 13 Left and center: Structures that emulate macroscopic toy gyroscopes with open (1a-c) and triply bridged topologies (2). Right: a fragment of the structure of MOF-5. (Reproduced from Ref. 66. (c) American Chemical Society, 2008.) 
distinct motions, ranging from simple $\mathrm{C}_{6}$-rotations of benzene- $\mathrm{d}_{6}$ at low temperatures to rather ill-defined $180^{\circ}$ phenyl flips of fluorobenzene- $\mathrm{d}_{5} \cdot{ }^{67}$

The large CSA associated with the carbonyl resonances in the ${ }^{13} \mathrm{C}$ cross polarization magic angle spinning (CPMAS) spectrum at room temperature of crystalline $\mathrm{Cr}(\mathrm{CO})_{3}\left(\eta^{6}-\mathrm{C}_{6} \mathrm{H}_{6}\right)$ indicates that the carbonyl moieties are rigid due to crystalline packing constraints. Conversely ${ }^{13} \mathrm{C}$ carbonyl and deuterium data of $\mathrm{Cr}(\mathrm{CO})_{3}\left(\eta^{6}-\mathrm{C}_{6} \mathrm{H}_{6}\right)$ included in $\beta$-CD selectively enriched in ${ }^{13} \mathrm{C}$ (carbonyl ligand) and ${ }^{2} \mathrm{D}$ (arene ligand) respectively, ${ }^{68}$ show that a fast motion of the guest molecule is present. The entire molecule does not rotate isotropically inside the cavity, but with a $\mathrm{C}_{6}$ rotation around the main molecular axis of symmetry. Interestingly the VT ${ }^{13} \mathrm{C}$ SSNMR spectra of $\left(\eta^{5}-\mathrm{C}_{5} \mathrm{H}_{5}\right)_{2} \mathrm{Mo}_{2}(\mathrm{CO})_{6}$ included in $\gamma$-CD can only be interpreted by fast motion of one half of the dimer inside the $\mathrm{CD}$ cavity, whereas the nonincluded $\left(\eta^{5}-\mathrm{C}_{5} \mathrm{H}_{5}\right) \mathrm{Mo}(\mathrm{CO})_{3}$ part is rigid due to strong interatomic interaction with neighboring molecules. ${ }^{69}$ Fast motion of the $\left(\eta^{5}-\mathrm{C}_{5} \mathrm{H}_{5}\right) \mathrm{Mo}(\mathrm{CO})_{3}$ part inside the hydrophobic cavity is explained by the weaker constrain forces.

\section{CONCLUSIONS}

In this chapter we demonstrated how SSNMR spectroscopy can contribute to understanding the structure and properties of supramolecular architectures. This topic is a very broad area with an extensive literature, and for this reason and the limited length of this chapter we have chosen to illustrate the potential role of SSNMR with select examples.

The use of a multinuclear and multiparametric approach in the SSNMR investigation allows to obtain information at the local level opening new perspectives in the prediction and design of supramolecular systems. In particular, HBs, polymorphism, intermolecular packing arrangements, and dynamics of molecular segments can be investigated in great detail, in most cases without the need for special sample preparation. Correlations between the chemical structure and the SSNMR data have been extensively established. Especially the isotropic chemical shift, the CSA and the dipolar correlations with specific structure features like internuclear distances and dynamics could be established for an increasing number of complex supramolecular architectures. Moreover quantitative correlations between the SSNMR parameters and specific bond angles and bond lengths have been obtained. Concerning the $\mathrm{HB}$ we reported how ${ }^{1} \mathrm{H},{ }^{13} \mathrm{C}$, and ${ }^{15} \mathrm{~N}$ chemical shifts and chemical shift tensors can provide information on the presence and the strength of the interaction, data which are not easily amenable to obtain by diffraction techniques.
Several correlations among NMR chemical shifts, geometrical parameters and computed data were also reported. We showed the versatility of the NMR technique in covering a wide timescale of fluxional processes from $10^{2}$ to $10^{-10} \mathrm{~s}$ by means of the analysis of its parameters such as the relaxation times $\mathrm{T}_{1}, \mathrm{~T}_{2}$, and $\mathrm{T}_{1 \rho}$.

We highlighted also that when weak forces are involved in a supramolecular structure there is a decrease of the energy barriers associated to the motion of groups or of entire molecules in the crystal packing. Often NMR data represent the best evidence to demonstrate that the extent of guest dynamics included in the host cavity is dependent on the degree of symmetry associated with the included molecule as well as on the strength of the host-guest interactions. Activation energy calculations for molecular processes in high-resolution SSNMR studies can reveal many interesting and sometimes controversial factors related to molecular reorientation and static or dynamic disorder found by single-crystal X-ray diffraction studies.

\section{ACKNOWLEDGMENTS}

We are indebted with Dario Braga and Fabrizia Grepioni for the helpful discussions.

\section{REFERENCES}

1. R. Gobetto, C. Nervi, M. R. Chierotti, et al. Chem.-Eur. J., 2005, 11, 7461

2. R. K. Harris, Solid State Sci., 2004, 6, 1025.

3. D. Braga, L. Maini, C. Fagnano, et al. Chem.-Eur. J., 2007, 13, 1222.

4. I. Schnell, S. P. Brown, H. Yee Low, et al. J. Am. Chem. Soc., 1998, 120, 11784.

5. D. Braga, G. Palladino, M. Polito, et al. Chem.-Eur. J., 2008, 14, 10149.

6. J. Brus and J. Jakes, Solid State Nucl. Magn. Reson., 2005, 27, 180

7. M. J. Duer, Solid-State NMR Spectroscopy, Blackwell Publishing Ltd., Oxford, 2004.

8. J. W. Steed and J. L. Atwood, Supramolecular Chemistry, John Wiley \& Sons, Ltd, Chichester, 2009.

9. A. Pines, M. G. Gibby, and J. S. Waugh, J. Chem. Phys., 1973, 59, 569.

10. E. Vinogradov, P. K. Madhu, and S. Vega, Chem. Phys. Lett., 1999, 314, 443.

11. B. C. Gerstein, R. G. Pembleton, R. C. Wilson, and L. M. Ryan, J. Chem. Phys., 1977, 66, 361.

12. E. Vinogradov, P. K. Madhu, and S. Vega, New Techniques in Solid-State NMR, Springer, Berlin, 2005, vol. 246, p. 33.

13. P. K. Madhu, Solid State Nucl. Magn. Reson., 2009, 35, 2. 
14. E. Vinogradov, P. K. Madhu, and S. Vega, Chem. Phys. Lett., 2002, 354, 193.

15. A. Lesage, D. Sakellariou, S. Hediger, et al. J. Magn. Reson., 2003, 163, 105.

16. S. Dusold and A. Sebald, Dipolar recoupling under magicangle spinning conditions, Annual Reports on NMR Spectroscopy, Academic Press, Inc., San Diego, CA, 2000, vol. 41, p. 185.

17. M. H. Levitt, Symmetry-based pulse sequences in magicangle spinning solid-state NMR, in Encyclopedia of Nuclear Magnetic Resonance, eds. D. M. Grant and R. K. Harris, Wiley, Chichester, 2002, vol. 9, p. 165.

18. W. Sommer, J. Gottwald, D. E. Demco, and H. W. Spiess, J. Magn. Reson., 1995, 113A, 131.

19. H. Geen, J. J. Titman, J. Gottwald, and H. W. Spiess, J. Magn. Reson., 1995, 114A, 264.

20. S. P. Brown and H. W. Spiess, Chem. Rev., 2001, 101, 4125 .

21. I. Schnell, A. Lupulescu, S. Hafner, et al. J. Magn. Reson., 1998, 133, 61.

22. S. P. Brown, Macromol. Rapid Commun., 2009, 30, 688.

23. M. G. Munowitz, R. G. Griffin, G. Bodenhausen, and T. H. Wang, J. Am. Chem. Soc., 1981, 103, 2529.

24. D. McElheny, E. de Vita, and L. Frydman, J. Magn. Reson., 2000, 143, 321.

25. T. Gullion and J. Schaefer, J. Magn. Reson., 1989, 81, 196.

26. D. D. Laws, H.-M. L. Bitter, and A. Jerschow, Angew. Chem., Int. Ed. Engl., 2002, 41, 3096.

27. D. P. Raleigh, M. H. Levitt, and R. G. Griffin, Chem. Phys. Lett. 1988, 146, 71.

28. T. Gullion and A. J. Vega, Prog. Nucl. Magn. Reson. Spectrosc., 2005, 47, 123.

29. A. Lesage, M. Bardet, and L. Emsley, J. Am. Chem. Soc., 1999, 121, 10987.

30. J. Schmidt, A. Hoffmann, H. W. Spiess, and D. Sebastiani, J. Phys. Chem. B, 2006, 110, 23204.

31. L. Frydman and J. S. Harwood, J. Am. Chem. Soc., 1995, 117, 5367.

32. J. Sopkova-de Oliveira Santos, V. Montouillout, F. Fayon, et al. New J. Chem., 2004, 28, 1244.

33. B. Moulton and M. J. Zaworotko, Chem. Rev., 2001, 101, 1629.

34. J. Brus, J. Dybal, P. Sysel, and R. Hobzova, Macromolecules, 2002, 35, 1253.

35. M. R. Chierotti and R. Gobetto, Chem. Commun., 2008, 1621.

36. G. A. Jeffrey, An Introduction to Hydrogen Bonding, Oxford University Press, Oxford, 1997.

37. R. Gobetto, C. Nervi, E. Valfrè, et al. Chem. Mater., 2005, 17, 1457.

38. R. K. Harris, P. Y. Ghi, R. B. Hammond, et al. J. Chem. Soc., Chem. Commun., 2003, 2834.

39. Z. Gu and A. McDermott, J. Am. Chem. Soc., 1995, 115, 4262 .
40. W. Veeman, Prog. NMR Spectrosc., 1984, 16, 193.

41. D. Braga, L. Maini, G. de Sanctis, et al. Chem._Eur. J., 2003, 1, 5538.

42. G. C. Levy and R. L. Lichter, Nitrogen-15 Nuclear Magnetic Resonance Spectroscopy, John Wiley \& Sons, Inc., New York, 1979.

43. A. Dos, V. Schimming, S. Tosoni, and H.-H. Limbach, J. Phys. Chem. B, 2008, 112, 15604.

44. D. Braga, S. L. Giaffreda, K. Rubini, et al. CrystEngComm, 2007, 9, 39.

45. M. Schultz-Dobrick, T. Metzroth, H. W. Spiess, et al. ChemPhysChem, 2005, 6, 315.

46. E. B. Brouwer, D. M. Gougeon, J. Hirschinger, et al. Phys. Chem. Chem. Phys., 1999, 1, 4043.

47. A. Brinkmann and A. P. M. Kentgens, J. Am. Chem. Soc., 2006, 128, 14758.

48. R. Tycko and Y. Ishii, J. Am. Chem. Soc., 2003, 125, 6606.

49. J. T. Nielsen, M. Bjerring, M. D. Jeppesen, et al. Angew. Chem., Int. Ed. Engl., 2009, 48, 2118.

50. C. Kehlet, M. Bjerring, A. C. Sivertsen, et al. J. Magn. Reson., 2007, 188, 216.

51. K. Takegoshi, S. Nakamura, and T. Terao, Chem. Phys. Lett., 2001, 344, 631.

52. S. Luca, W.-M. Yau, R. Leapman, and R. Tycko, Biochemistry, 2007, 46, 13505.

53. S. K. Nurly and G. A. Pestko, Science 1985, 299, 23.

54. K. Guckian, B. A. Scheitzer, X.-A. Ren, et al. J. Am. Chem. Soc., 1996, 118, 8182.

55. E. J. Corey and M. C. Noe J. Am. Chem. Soc., 1996, 118, 319.

56. S. P. Brown, T. Schaller, U. P. Seelbach, et al. Angew. Chem., Int. Ed. Engl., 2001, 40, 717.

57. S. P. Brown, I. Schnell, J. D. Brand, et al. J. Am. Chem. Soc., 1999, 121, 6712.

58. M. R. Chierotti and R. Gobetto, Eur. J. Inorg. Chem., 2009, 18, 2581.

59. M. E. Smith, Multinuclear Solid State NMR of Inorganic Materials, Pergamon Materials Series, Pergamon-Elsevier Science, Oxford, 2002, vol. 6.

60. D. Allion and C. P. Slichter, Phys. Rev. Lett., 1964, 12, 168.

61. K. Schmidt-Rohr and H. W. Spiess, Multidimensional Nuclear Magnetic Resonance and Polymers, Academic Press, London, 1994.

62. J. R. Lyerla, High-resolution NMR of glassy amorphous polymers, in Methods in Stereochemical Analysis, High Resolution NMR Spectroscopy of Synthetic Polymers in Bulk, ed. R. A. Komoroski, VCH Deerfield Beach, 1986, vol. 7, p. 63.

63. R. R. Vold, Deuterium NMR studies of dynamics in solids and liquid crystals, in Nuclear Magnetic Resonance Probes of Molecular Dynamics, ed. R. Tycko, Kluwer Academic Publishers, Dordrecht, 1994, pp. 27-112. 
64. M. Cutaijar, S. E. Ashbrook, and S. Wimperis, Chem. Phys. Lett., 2006, 423, 276.

65. Y. J. Lee, T. Murakhtina, D. Sebastiani, and H. W. Spiess, J. Am. Chem. Soc., 2007, 129, 12406.

66. S. L. Gould, D. Tranchemontagne, O. M. Yaghi, and M. A. Garcia-Garibay, J. Am. Chem. Soc., 2008, 130, 3246.
67. C. Moon, G. Brunklaus, D. Sebastiani, et al. Phys. Chem. Chem. Phys., 2009, 11, 9241.

68. S. Aime, H. C. Canuto, R. Gobetto, and F. Napolitano, Chem. Commun., 1999, 281.

69. S. Aime, M. R. Chierotti, R. Gobetto, et al. Eur. J. Inorg. Chem., 2008, 2008, 152. 